ISSN: 0514-7336 — ISSN electrónico: 2386-3943

DOI: https://doi.org/10.14201/zephyrus20218887110

\title{
ENTERRARSE EN COMUNIDAD: MECANISMOS PARA EL ANÁLISIS Y LA RECONSTRUCCIÓN DEL PALEOPAISAJE FUNERARIO DE LAS NECRÓPOLIS TARTÉSICAS
}

\section{Burying oneself in Community: Mechanisms for the Analysis and Reconstruction of the Funerary Paleolandscape of the Tartessian Necropolises}

\author{
Esther Rodríguez González y Pablo Paniego Díaz
}

Instituto de Arqueología (CSIC-Junta de Extremadura). Plaza de España, 15. 06800 Mérida (Badajoz. Correo-e: esther.rodriguez@iam.csic.es; pablo.paniego@iam.csic.es. ID ORCID: https://orcid.org/0000-0002-5813-9035; https://orcid.org/0000-0002-6218-0938

Recepción: 4/01/2021; Revisión: 3/05/2021; Aceptación: 28/07/2021

Resumen: En la actualidad se conoce un número destacado de necrópolis tartésicas fechadas en la i Edad del Hierro tanto en el valle del Guadalquivir como en el valle del Guadiana. El conocimiento que tenemos de estas deriva del estudio de sus enterramientos y sus ajuares, sin que hasta el momento hayan sido analizadas dentro del paisaje y del modelo de poblamiento del que forman parte. Con el objetivo de reconstruir el paisaje antiguo en el que se ubicaron estas necrópolis y detectar un patrón en la elección de los lugares para su ubicación, proponemos en este trabajo un método de análisis geográfico en el que se combinan los datos LidAR, la fotografía histórica y los registros de inundaciones. Esta metodología se ha puesto en práctica en el análisis de las necrópolis del valle medio del Guadiana fechadas entre los ss. viI y v a. C. y el resultado nos permite definir la existencia de un patrón que conecta estos espacios funerarios con tradiciones de origen oriental.

Palabras clave: Tarteso; I Edad de Hierro; necrópolis; paisaje funerario; análisis espacial; LiDAR.

Aвstract: Many tartessian necropolises dating from the Early Iron Age are well-known at present in both the Guadalquivir Valley and the Guadiana Valley. The knowledge we have of these funerary spaces comes from the study of their burials and their grave goods. Issues related to landscape and settlement patterns have not yet been addressed. In this work we propose a methodological analysis which combines LiDAR data, historical photography, and flood records. The main objectives of this analyses are to reconstruct the ancient landscape in which these necropolises are located and to discover the possible existence of a pattern related to these locations. This methodology has been put into practice in the analysis of the necropolises of the Middle Guadiana Valley dated between the $7^{\text {th }}$ and $5^{\text {th }}$ centuries BC. The result allows us to observe a pattern that connects these funerary spaces with Eastern origin traditions.

Key words: Tartessos: Early Iron Age; Necropolises; Funeral Landscape; Spatial Analysis; Lidar. 


\section{La definición de un 'patrón de asentamiento' para la localización de las necrópolis tartésicas $^{1}$}

Desde que G. Bonsor iniciase sus trabajos de excavación y documentación en los túmulos funerarios de los Alcores (Bonsor, 1899), los conocimientos en torno a los espacios funerarios de la cultura tartésica no han dejado de crecer, incorporando nuevos hallazgos que han permitido configurar el paisaje funerario de los valles de los ríos Guadalquivir y Guadiana durante la I Edad del Hierro. Todas estas necrópolis han sido objeto de análisis y publicaciones en las que se abordan aspectos como la organización interna de sus espacios, los ritos presentes en ellas o su conexión con otras áreas peninsulares, así como la naturaleza y composición de sus ajuares, un aspecto fundamental para establecer relaciones culturales y cronológicas (Ruiz Delgado, 1989; Ruiz Mata y Pérez, 1995; Torres, 1999, $2005,2017)$, que han focalizado el debate en torno a la filiación cultural de los individuos enterrados (Álvarez Martí-Aguilar, 2009, 2010). Todo ello ha permitido concluir de forma mayoritaria que las necrópolis adscritas al horizonte tartésico cuentan con una fuerte influencia oriental, tanto en los rituales documentados como en los ajuares que presentan -una revisión reciente sobre la identidad del mundo funerario tartésico en Gómez Peña, 2018-.

Frente a ello, nada se ha sugerido acerca de la situación que ocupan estas necrópolis en el territorio. Apenas tres trabajos de investigación abordan este debate hasta el momento (Belén, 2001; Torres, 1999, 2017), sin que en ninguno de ellos el objetivo perseguido sea el análisis de los accidentes geográficos que rodean a estos espacios funerarios y cómo estos condicionan a las poblaciones a seleccionar la

1 Este trabajo se ha realizado en el marco del Proyecto de Investigación "Construyendo Tarteso 2.0. Análisis constructivo, espacial y territorial de un modelo arquitectónico en el valle medio del Guadiana” (PID2019-108180GB-100, 2020-2023). Así mismo, queremos mostrar nuestro agradecimiento a A. Rodríguez Ramírez, profesor del Dpto. de Ciencias de la Tierra de la Univ. de Huelva, por sus indicaciones acerca de la reconstrucción del paleocauce del Guadiana, que, sin duda, han redundado en la mejora de este manuscrito; así como a los evaluadores del trabajo, cuyos comentarios han servido para mejorar el texto original. ubicación para posicionar sus enclaves, en este caso las necrópolis. Muestra de ello es la ausencia de una cartografía en la que se integren todas las evidencias funerarias que permita tener una visión de conjunto del paisaje funerario del so peninsular durante la I Edad del Hierro.

A pesar de ello, de uno de estos trabajos de investigación se extrae la definición del patrón de asentamiento que es común para las necrópolis de la I Edad del Hierro de la Baja Andalucía, Extremadura y Portugal, que nosotros tomaremos como punto de partida para la realización de este trabajo. La definición indica que estos espacios ocupan puntos en altura, cercanos a un poblado y separados del mismo por una vaguada por la que en ocasiones discurre un curso fluvial o camino (Torres, 1999: 184). Como es lógico, los hallazgos arqueológicos que han sucedido a la redacción de esta definición hacen que esta deba ser matizada, pues no todas las necrópolis de la I Edad del Hierro del so peninsular ocupan espacios en altura, ni todos los poblados a los que estarían asociados nos resultan conocidos, por lo que no podemos generalizar el hecho de que exista una relación directa entre necrópolis y poblados, aunque sí suponerla.

En esta ocasión, el interés de nuestra investigación se centra en la referencia que esta definición hace a la existencia de una vaguada que se encarga de separar el territorio de los vivos del espacio de los muertos. En este sentido, resultaría conveniente matizar si dicha vaguada estuvo en la Antigüedad ocupada por un curso de agua o camino, dado que algunos estudios ya han sugerido la importancia de estos últimos como mecanismo de territorialización y reflejo de la existencia de un culto a los antepasados (Almagro-Gorbea, 1996: 70). El problema derivado de este estudio que define la preponderancia de los caminos frente a la existencia de cursos de agua (Torres, 1999: 160) son los recursos empleados para definir el patrón, pues el uso de calzadas romanas e incluso caminos actuales para definir la separación o considerar el aislamiento de una necrópolis con respecto al resto del territorio resulta un ejercicio arriesgado, pues desconocemos si estas vías terrestres estaban en uso en las mismas cronologías que las necrópolis.

Ante el desconocimiento que gira en torno al paisaje en el que se insertan las necrópolis tartésicas 
del so peninsular, y teniendo presente la carga simbólica que la elección del lugar puede tener dentro del ritual de enterramiento, consideramos que el estudio y la reconstrucción del paleopaisaje en el que se ubican las necrópolis se antoja fundamental de cara a poder precisar la elección de su ubicación y definir los elementos que las separan del resto del territorio, desechando el uso de la geografía actual como escenario, pues debemos tener presentes las grandes transformaciones que el paisaje ha experimentado en los últimos siglos, tanto por el auge de las ciudades como por la expansión de la agricultura. Ello ha llevado a desdibujar, e incluso a transformar por completo, los entornos que un día rodearon a las necrópolis y los poblados protohistóricos del so peninsular, haciendo inservible la visión que actualmente tenemos del paisaje como marco de análisis.

Aunque lo ideal sería analizar el contexto de todas las necrópolis tartésicas conocidas, dada la alta densidad de evidencias que se concentran solo en el valle medio del Guadalquivir, hemos considerado más adecuado emprender este estudio por regiones, seleccionando el valle medio del Guadiana como primera área de investigación (Fig. 1). La incorporación de este valle al horizonte tartésico parece estar ya fuera de toda discusión, más cuando el

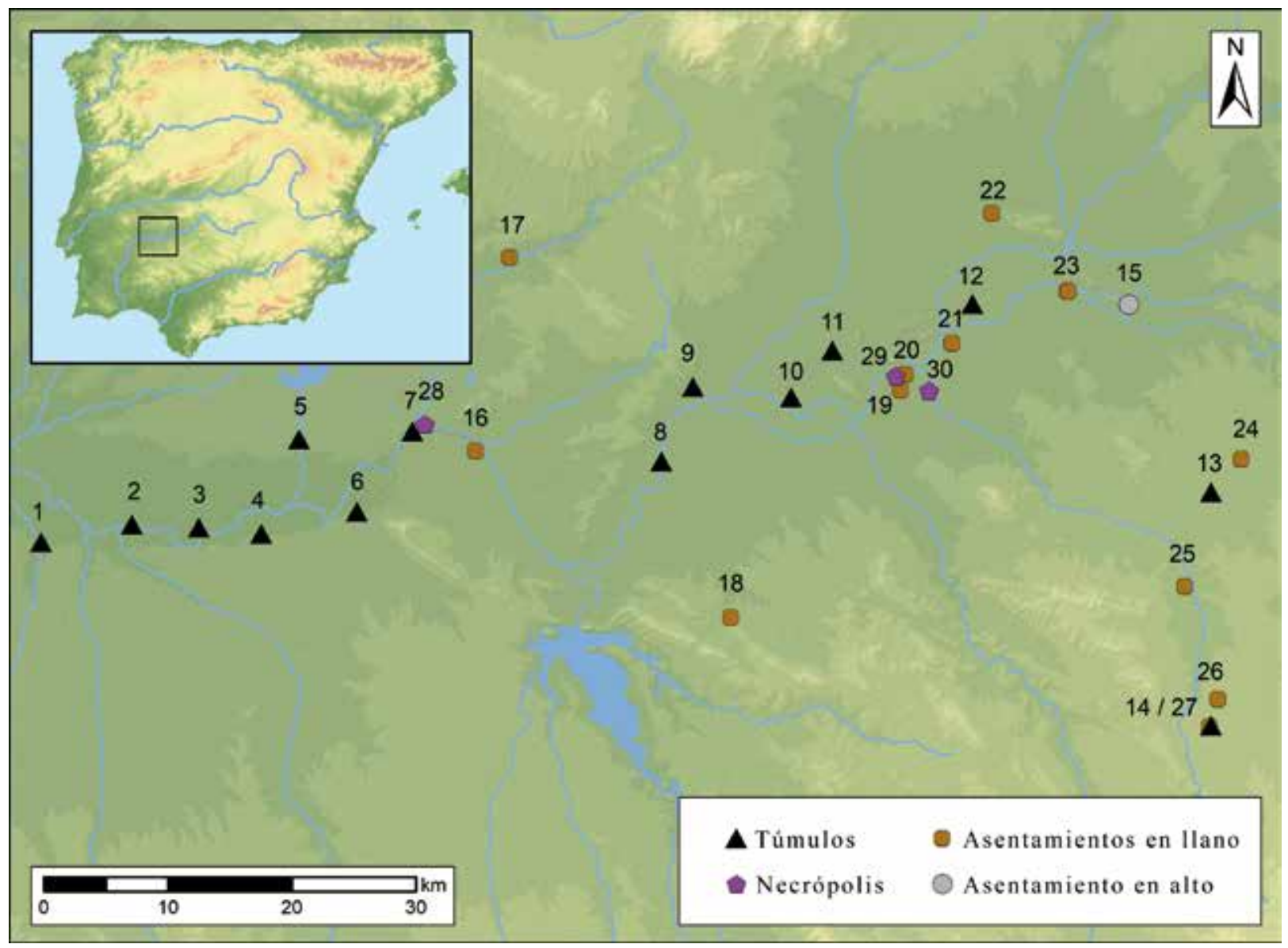

Fig. 1. Mapa del poblamiento del valle medio del Guadiana durante los ss. VII-V a. C.: 1. Huerta de Don Mateo; 2. Casas del Cerro de la Barca; 3. Cañada la Virgen; 4. Miraflores; 5. Lácara; 6. Turuñuelo de Mérida; 7. El Tiriñuelo; 8. Turuñuelo, Villagonzalo; 9. Las Madalenas; 10. Casas del Turuñuelo: 11. Las Lomas; 12. La Aliseda; 13. La Mata; 14. Cancho Roano; 15. El Tamborrio; 16. Escuela de Hostelería, Mérida; 17. El Chaparral; 18. El Palomar; 19. La Marquesa; 20. Medellin; 21. La Veguilla; 22. Cerro Manzanillo; 23. Cerro de la Barca-Torruco; 24. Media Legua-2; 25. La Carbonera; 26. La Mata de Cancho Roano; 27. Las Reyertas; 28. Necrópolis de Aljucén; 29. Necrópolis de El Pozo; 30. Necrópolis de Valdelagrulla (elaborado sobre MDT de $25 \mathrm{~m}$ de resolución del Servicio Global de Tierras de Copernicus-CGLS). 
contexto objeto de análisis son las necrópolis, pues las similitudes que las tumbas del Guadalquivir y el Guadiana presentan, en lo que a ritos y ajuares se refiere, son una buena muestra de la conexión cultural que existe entre ambos territorios. Así, la crisis que el núcleo de Tarteso experimentó a finales del s. vi a. C. se traducirá en la inauguración de un nuevo modelo de poblamiento en el valle medio del Guadiana que ha sido identificado, sin reservas, como la etapa final de Tarteso (Celestino y López Ruiz, 2020; Celestino y Rodríguez González, 2017; Rodríguez González, 2018, 2020a).

La carencia de análisis espaciales en torno a las necrópolis del Guadiana Medio nos permite emplear su territorio y sus necrópolis como laboratorio de pruebas para conocer la efectividad del modelo metodológico aquí propuesto ${ }^{2}$. Debemos además tener presente la fuerte transformación que el paisaje de esta región ha sufrido desde la década de los 50 del pasado siglo como consecuencia de la construcción de varios pantanos que regulan el cauce del río Guadiana. A la construcción de las presas debemos sumar la reparcelación e incorporación de los cultivos de regadío y la reforestación de las tierras que se extienden en los márgenes del Guadiana y de sus afluentes, lo que desdibuja la imagen exacta de la ubicación que determinados asentamientos tuvieron en la Antigüedad, lo que no ha permitido evaluar las condiciones de su localización y, por lo tanto, su significado.

Ante este vacío de información, el objetivo de este trabajo es contribuir en la reconstrucción del paleopaisaje de esta región del Guadiana, dado que es el mecanismo más idóneo para conocer la apariencia que este territorio tendría durante la I Edad del Hierro, devolviendo así los asentamientos a su posición y contexto espacial original. Solo de ese modo podremos considerar la existencia de

2 De gran interés habría sido incluir las necrópolis del actual territorio de Portugal, al menos las que jalonan el río Guadiana, sin embargo, no resulta posible acceder a la cartografía necesaria para llevar a cabo un estudio de esta naturaleza, siendo esta la razón por la que necrópolis como la Herdade da Chaminé (Elvas), Monte da Cardeira (Alandroal), Herdade das Casas (Redondo) o Cerro Furado (Beja) han quedado al margen de este estudio a pesar de que comparten cronología y ritual con las necrópolis del valle medio del Guadiana. una intencionalidad en la elección de los espacios. Dicha intencionalidad podrá posteriormente traducirse en la pervivencia de tradiciones que dentro de una sociedad han quedado plasmadas en aspectos como la elección de los lugares donde fueron depositados sus difuntos.

El punto de partida del trabajo se asienta en el análisis topográfico de la necrópolis de El Pozo (Medellín, Badajoz), la que mayor extensión y riquezas presenta dentro del conjunto de necrópolis tartésicas del Guadiana Medio. Aunque durante las labores de excavación de este espacio nunca se emprendió un análisis del territorio circundante a la necrópolis, la observación del territorio permitió al director de las intervenciones afirmar que "... la topografía que ofrece la necrópolis permite suponer que en la Antigüedad ocuparía parte de un brazo fluvial ocasionalmente inundable del río, cuyas márgenes probablemente serían de límites variables dada la gran escorrentía que ha caracterizado al Guadiana hasta su regulación por los pantanos construidos a mediados del s. xx..." (Almagro-Gorbea, 2006a: 20).

Con la finalidad de corroborar la relación entre los cursos de agua y las necrópolis, hemos comenzado por recopilar toda la documentación arqueológica correspondiente a los hallazgos funerarios realizados en el Guadiana Medio, fechados entre los ss. VII-v a. C. La reconstrucción del paisaje antiguo ha sido posible gracias a la combinación de varias herramientas, actualmente a disposición del usuario entre la documentación cedida por el Centro $\mathrm{Na}$ cional de Información Geográfica -CNIG-, dependiente del Instituto Geográfico Nacional -IGN- y el Sistema de Información Territorial de Extremadura -SITEX-. El uso de la fotografía histórica, concretamente de los fotogramas de los vuelos americanos A (1945-1946) у в (1956-1957), los Modelos Digitales del Terreno -MDT- y los datos LiDAR, dentro de los cuales se ha incorporado como novedad la información cedida por el Ministerio para la Transición Ecológica y el Reto Demográfico a través de la Confederación Hidrográfica del Guadiana - CHG- correspondiente a las series de inundaciones analizadas y registradas a lo largo de la cuenca del Guadiana y de los datos de Áreas con Riesgo Potencial Significativo de Inundación -ARPSI-, nos ha 
y la reconstrucción del paleopaisaje funerario de las necrópolis tartésicas

permitido detectar los paleocauces del río. Con ello, se han podido ubicar las necrópolis en su espacio original y analizar la relación que guardan con los antiguos cursos de agua, hoy amortizados o desviados de su curso original para su aprovechamiento en los cultivos de regadío.

Así, la combinación de los datos arqueológicos y espaciales nos ha permitido añadir una característica más a la definición del 'patrón de asentamiento' de los ambientes funerarios del valle medio del Guadiana durante la I Edad del Hierro que, a falta de efectuar los análisis en los enclaves del Guadalquivir Medio, a bien seguro actúa como un antecedente perfecto del patrón que posiblemente se detecte en esta última región, así como en otras áreas del Mediterráneo. Todo ello aporta un complemento a los estudios que hasta la fecha solo han abordado el análisis de los rituales de enterramiento y la clasificación y datación de los ajuares documentados en las tumbas.

\section{2. ¿Quién fue enterrado en el valle medio del Guadiana durante la I Edad del Hierro y dónde?}

Hasta la fecha, un total de 18 enclaves (Fig. 2) han sido identificados como necrópolis a lo largo

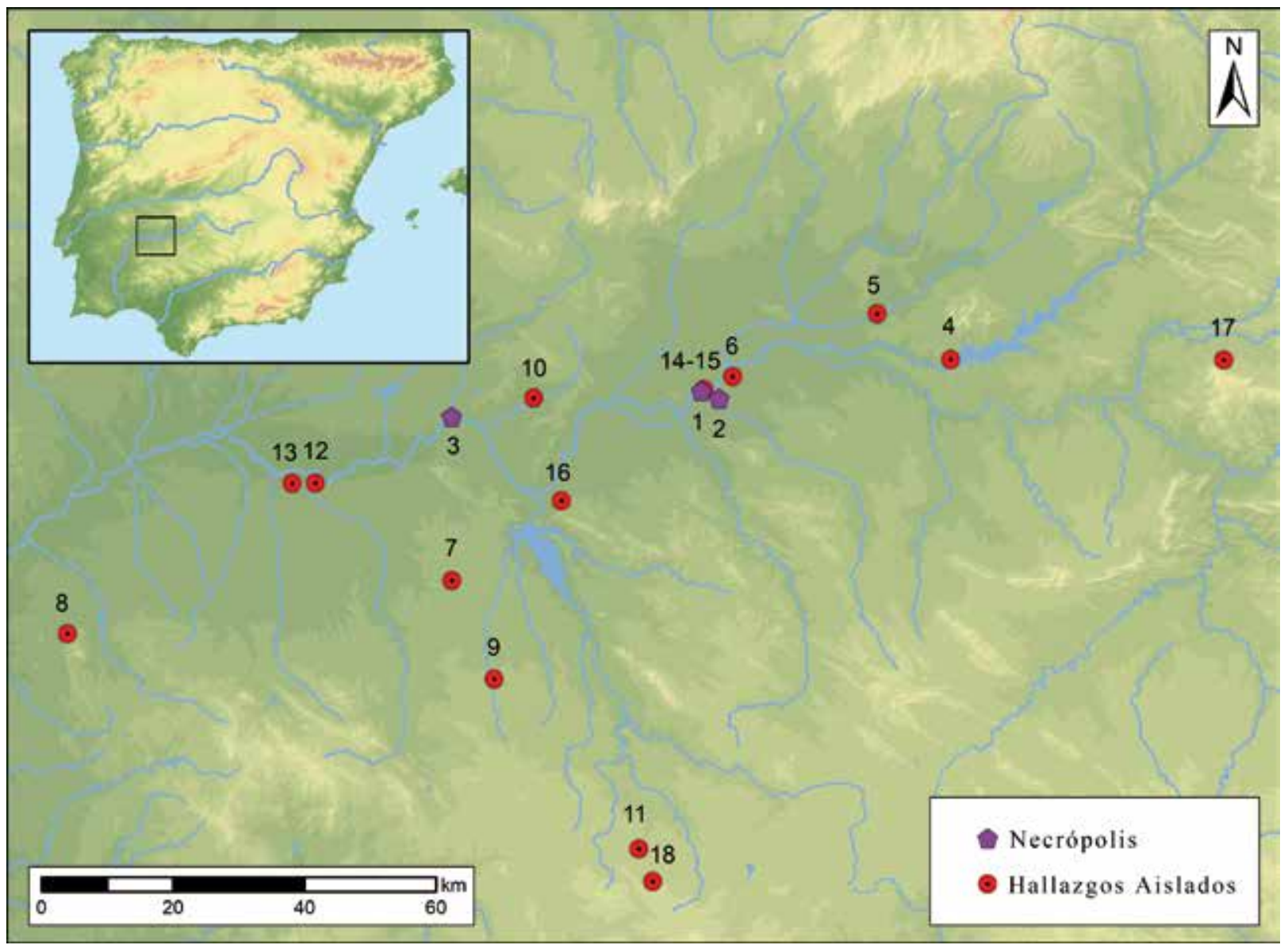

FIG. 2. Mapa de localización de las evidencias funerarias documentadas en el valle medio del Guadiana e inscritas en la I Edad del Hierro. En el conjunto se distinguen hallazgos aislados y necrópolis excavadas: 1. Necrópolis de El Pozo; 2. Necrópolis de Valdelagrulla; 3. Necrópolis de Aljucén; 4. Los Tercios; 5. Gargáligas; 6. La Veguilla; 7. Campo Viejo; 8. El Romal; 9. Molino de Abajo; 10. Los Barrillos; 11. Las Mallas; 12. El Charro; 13. El Cuco; 14. Calle Mayor; 15. Antiguo Campo de Fútbol; 16. Jarro de la Zarza; 17. Jarro de Siruela; 18. Timiaterio de Villagarcía de la Torre (elaborado sobre MDT de $25 m$ de resolución del Servicio Global de Tierras de Copernicus-CGLS). 
de la cuenca media del Guadiana y las tierras que se extienden hacia el s del cauce del río (Jiménez Ávila, 2016). Sin embargo, no todos han proporcionado un volumen de información homogéneo, pues la gran mayoría de ellos, un total de 13, son hallazgos aislados carentes de contexto que, dada la naturaleza de los materiales recuperados y la información trasmitida por los protagonistas del hallazgo, ha llevado a interpretarlos como espacios funerarios. Lamentablemente, la mayor parte de estos materiales proceden de actividades arqueológicas incontroladas, por lo que, ante las serias dudas sobre el lugar exacto de procedencia de las piezas, hemos decidido dejarlas al margen en este estudio.

Frente a ellos sí contamos con cuatro ejemplos (Fig. 3) que han sido objeto de intervenciones arqueológicas, lo que nos permite extraer una imagen del paisaje funerario del valle medio del Guadiana durante los ss. VII-v a. C. Es curioso que tres de estos enclaves se concentren en el entorno del territorio de Medellín, lo que ha permitido esbozar una nueva hipótesis de trabajo que ahonda en el papel que estas necrópolis pudieron desempeñar y su relación con el poblamiento de la cuenca media del Guadiana (Rodríguez González, 2018: 255; 2020b: 281-282).

La primera necrópolis incluida en este estudio es la de Mengabril. Fue objeto de una breve intervención por parte de M. Almagro-Gorbea (1977: 280) después de que durante las labores de extracción de arenas del río se documentaran un conjunto de urnas. Según los datos recopilados, se trata de una

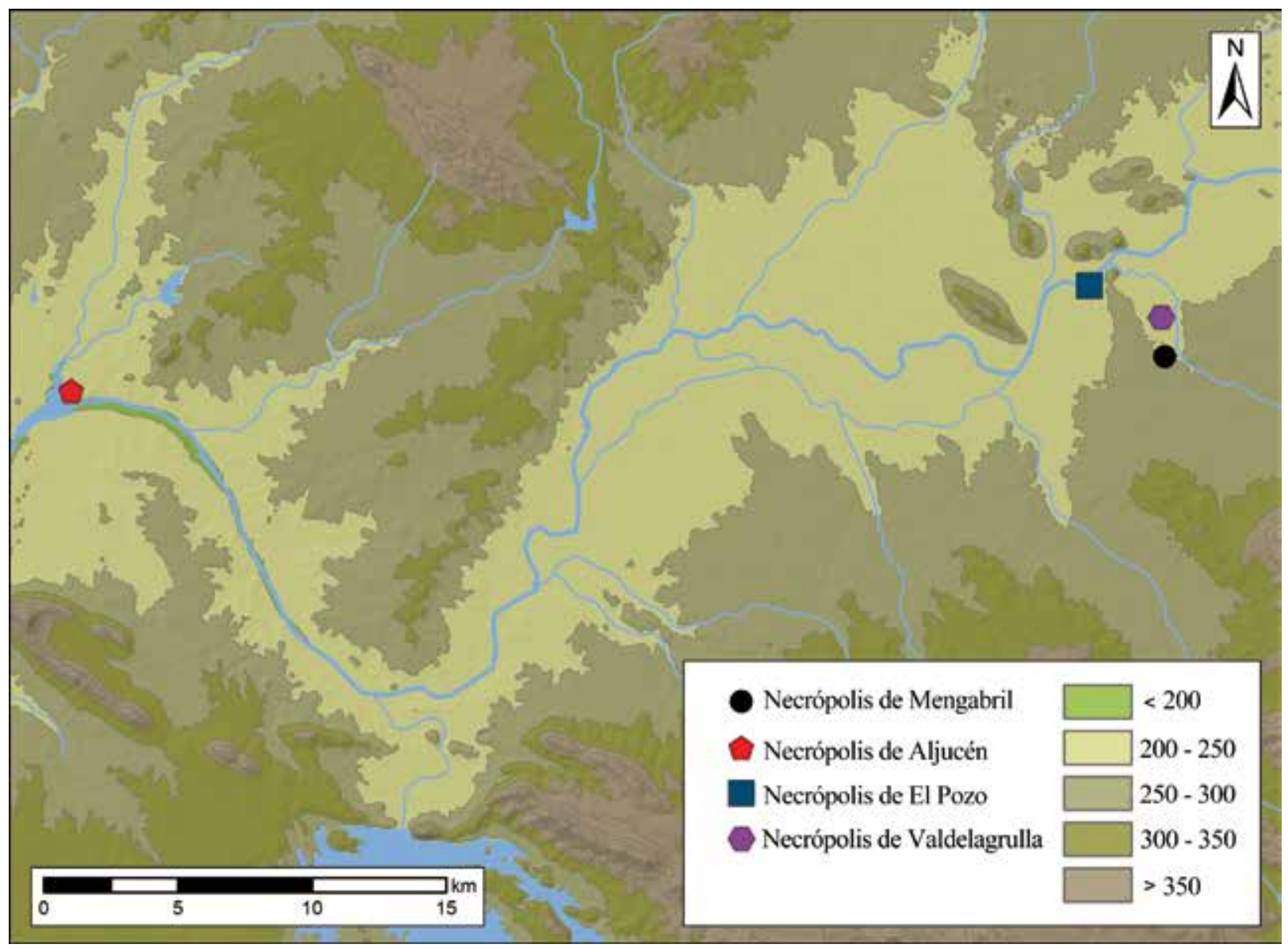

FIG. 3. Mapa de localización de los enclaves objeto de análisis en este trabajo (elaborado sobre MDT de 25 m de resolución del Servicio Global de Tierras de Copernicus-CGLS). 
necrópolis tumular, similar a la denominada de El Pozo, con estructuras fabricadas con cantos de río. Dada la aparente menor densidad de enterramientos y la pobreza de los ajuares nunca se optó por su excavación. Tan solo se documentó una sepultura compuesta por una urna cuyo perfil parece derivar de las formas típicas de las ánforas púnicas. Junto a esta pieza se recuperó otro conjunto de materiales fuera de contexto entre los que se citan dos urnas esféricas - una de ellas correspondiente al tipo Cruz del Negro-, cuatro vasos à chardón, dos urnas de fondo redondeado, seis platos y dos copas. El conjunto fue fechado en origen entre los ss. VI y $\mathrm{v}$ a. C. (Almagro-Gorbea, 1977: 284), aunque su posterior revisión arrojó unas cronologías que abarcan un período entre el 650-550 a. C. (Torres, 1999: 107), una fecha que retrasa considerablemente su momento de uso.

En las proximidades de Mengabril se localiza la necrópolis de Medellín, conocida comúnmente como 'Necrópolis de El Pozo' para poder así diferenciarla del resto de núcleos funerarios que se localizan en el entorno de la localidad de Medellín. Fue descubierta de forma casual en 1960 durante las labores de apertura de un pozo de riego, tareas en las que se pudo documentar un lote de materiales del que procede el kylix de Eucheiros (Almagro-Gorbea, 1970). En 1969 se iniciaron los trabajos de prospección del entorno del pozo, unos trabajos que rápidamente se completaron con el inicio de las excavaciones. En total se han llevado a cabo cinco campañas de excavación -1969, 1970, 1982, 1985 y 1986- que han permitido excavar una extensión aproximada de $370 \mathrm{~m}^{2}$ en los que se estima que se han documentado unas 300 estructuras (Almagro-Gorbea, 2006b: 23-24; 2017: 143).

Según la documentación extraída de las diferentes campañas de excavación, la necrópolis de El Pozo cuenta con tres fases de ocupación diferenciadas por el tipo de rito empleado en las mismas (Almagro-Gorbea, 2008a: 881-882). La Fase I se corresponde con enterramientos en urna dentro de hoyo, fechados entre la segunda mitad del s. viI e inicios del s. vi a. C. Los cadáveres correspondientes a este ritual habrían sido cremados en un ustrinum

Ediciones Universidad de Salamanca / 요 colectivo cuya localización resulta desconocida, por lo que se ha supuesto su posible destrucción por las crecidas del Guadiana (Almagro-Gorbea, 2008c: 956; 2017: 145). Dentro de las urnas se depositaban los restos óseos restantes de la cremación, limpios y cribados, sin cenizas. La Fase II se define por un cambio en el tipo de ritual, con el empleo de enterramientos en busta o fosas de cremación individuales en las que junto a los restos del difunto se depositaba su ajuar. Junto a este rito se han localizado algunos silicernia o depósitos de ofrendas sin restos óseos humanos. Esta fase ha sido fechada entre el 575 y el 500 a. C. Por último, la Fase III combina ambos ritos, pues se ha documentado algún enterramiento residual en urna dentro de hoyo, junto a los busta característicos de la fase anterior. Esta última fase se ha fechado entre el 500 y el 475 a. C.

Común a ambos tipos de enterramientos es la señalización de los mismos mediante encanchados construidos a partir de guijarros procedentes del río Guadiana cuyo tamaño y forma difiere en cada uno de los casos, aunque parece repetirse un patrón en cuanto a la forma adoptada, de tendencia circular para los enterramientos en urna y rectangular para los busta (Almagro-Gorbea, 2008c: 962-963). A la presencia de estos encanchados se le ha otorgado un significado ritual y simbólico como marcadores de las tumbas; sin embargo, y dadas las crecidas del río que afectaban a la necrópolis, cabe suponer que estos podrían haber estado también destinados a proteger las tumbas de los aportes realizados por las corrientes del río aprovechando el material más abundante en la zona.

A 2,7 km al sE de la necrópolis de El Pozo se localiza la de Valdelagrulla, documentada en el año 2012 durante las labores de construcción del Gasoducto Mérida-Miajadas (Menéndez et al., 2013), por lo que el área de excavación se restringe al espacio afectado por la obra, un corte de $14 \mathrm{~m}$ de ancho por $30 \mathrm{~m}$ de longitud. El desbroce de la vegetación permitió documentar la presencia de manchas oscuras que fueron delimitadas para su posterior excavación. En total se registraron 87 de esas manchas, de las cuales 48 han sido adscritas a la necrópolis protohistórica, mientras que el resto corresponden a

Zephyrus, LXXXVIII, julio-diciembre 2021, 87-110 
huellas de uso agrícola del espacio en época romana y, fundamentalmente, andalusí (Menéndez et al., 2013: 1005).

Todas las tumbas intervenidas corresponden al ritual de busta, fosas de forma ovalada y alargada excavadas en el suelo donde fueron directamente cremados los cadáveres, de ahí la presencia de arcilla refractaria en el contorno de las fosas y los tonos negros y rojos de los sedimentos de su interior. Las dimensiones de las fosas varían entre 1 y $2 \mathrm{~m}$ de extensión, con profundidades que alcanzan los 35 cm (Menéndez et al., 2013: 1007). Los ajuares se concentran en uno de los extremos de la fosa, junto a los restos óseos del difunto resultado de la cremación. Del conjunto de enterramientos individualizados, 30 de ellos cuentan con material, pero solo 12 pueden considerarse apropiadamente ajuares, pues el resto únicamente se corresponde con materiales asociados al relleno del bustum (Menéndez et al., 2013: 1010).

El análisis espacial de las estructuras excavadas y el hecho de que se agotase la secuencia estratigráfica con el objetivo de corroborar la ausencia de enterramientos en urna, siguiendo así el mismo esquema que la necrópolis de El Pozo, permite concluir que la disposición de los enterramientos de Valdelagrulla es bastante homogénea en tanto en cuanto no se han documentado superposiciones de tumbas, sino que estas se extienden por el espacio evitando invadir la zona ocupada por las tumbas aledañas. En cuanto a los ajuares, y a diferencia de los enterramientos de El Pozo donde el elenco material es bastante homogéneo, lo que refleja una sociedad igualitaria, en Valdelagrulla hay tumbas sin ajuar, frente a otros casos, como la XLVI (Menéndez et al., 2015), que destacan por su riqueza material.

Fuera del núcleo de necrópolis que se localizan en el entorno del actual municipio de Medellín, en 1987 se localizaron en la 'Huerta del Murciano' (Mérida) los restos de una necrópolis de incineración en hoyo fechada en la i Edad del Hierro (Enríquez, 1991; Enríquez y Domínguez de la Concha, 1991). La necrópolis se localiza justo en la confluencia entre los ríos Guadiana y Aljucén, de quien toma el nombre, y ocupa un espacio de $3 \times 2 \mathrm{~m}$.

Ediciones Universidad de Salamanca / 용
Durante las labores de excavación pudieron recuperarse siete conjuntos, seis de ellos correspondientes a enterramientos en urna, y un caso aislado del que solo se recuperó una ofrenda compuesta por un plato y un cuenco. Las urnas se documentaron depositadas en pequeños hoyos practicados en el suelo natural, sujetos con cantos de río (Enríquez y Domínguez de la Concha, 1991: 37). En el interior de las urnas fueron introducidos los restos óseos limpios, sin presencia de cenizas, junto con algunos objetos menores correspondientes al ajuar funerario. Tras el enterramiento, las urnas fueron tapadas con platos. Aunque solo se recuperaron dos in situ, la presencia de fragmentos de plato en el interior de algunas urnas invita a pensar que todas estuvieron cubiertas mediante este sistema.

Aunque por los restos documentados se sabe que el rito presente en esta necrópolis es el de cremación, no hay huella alguna que permita acreditar que los cuerpos fueron incinerados próximos al lugar de enterramiento, pues no se recuperaron restos de un posible ustrinum, ni cenizas asociados a este tipo de ritual. No obstante, no se puede descartar esta posibilidad, pues la necrópolis se localiza dentro de una propiedad privada que cuenta con varias construcciones, por lo que no pudo excavarse todo el espacio que rodea a los conjuntos recuperados. Así mismo, no debemos pasar por alto la proximidad de este espacio funerario al actual límite del embalse de Montijo, por lo que cabe la posibilidad de que parte de esta necrópolis esté oculta bajo sus aguas. En este sentido cabe recordar que del embalse de Montijo proceden los restos de cuatro espadas pistiliformes que en ocasiones se han puesto en relación con la deposición de armas en los fondos de los ríos como práctica funeraria durante el Bronce Final (Ruiz Gálvez, 1995; Torres, 2017: 360-361).

Desde el descubrimiento y excavación de los enterramientos de Aljucén, estos fueron puestos en relación con los enterramientos en urnas documentados hasta aquel momento en la necrópolis de Medellín. A pesar de las similitudes que presentan tanto en el rito empleado como en los materiales que componen los ajuares, hay que resaltar la diferencia en el contenedor empleado, pues mientras

Zephyrus, LXXXVIII, julio-diciembre 2021, 87-110 
las urnas de la necrópolis de El Pozo corresponden a la tipología de Cruz del Negro, las de Aljucén son pithoi. Solo una de las tumbas documentadas en Medellín, la 82/25 (Almagro-Gorbea, 2006d: 130131), tiene entre los objetos presentes en el enterramiento los restos de un pithos, que en este caso no fue utilizado como contenedor de las cenizas, sino que se documentó fragmentado y sobre el hoyo en el que fueron depositados los huesos cremados del difunto dentro de una urna de cerámica gris. Los pithoi son recipientes característicos de los ambientes coloniales fenicios, tanto orientales como occidentales, aunque también están presentes en contextos indígenas donde la forma sería finalmente imitada en los alfares locales. Aunque tradicionalmente ha sido caracterizado como un recipiente contenedor destinado al almacenamiento y transporte (Pla, 2014: 691-692), se ha detectado su uso secundario en contextos funerarios tanto del levante peninsular como del sur; sin embargo, el hallazgo más septentrional y alejado del área de influencia fenicia es el de Aljucén. Como hasta la fecha no se ha definido el poblado o asentamiento al que estaría vinculada esta necrópolis (Enríquez y Domínguez, 1991: 36), solo un análisis arqueométrico de sus materiales permitiría definir si se trata de producciones locales del Guadiana o, por el contrario, de materiales importados procedentes de ambientes costeros. No obstante, el hallazgo de este tipo de enterramientos viene a afianzar la existencia de una influencia oriental en las tierras del interior manifestada en la pervivencia de ritos en los contextos funerarios tartésicos del Guadiana.

La vinculación de estas necrópolis con núcleos de población es bastante incierta. Así, las necrópolis de Mengabril, Valdelagrulla y Aljucén han sido caracterizadas como necrópolis rurales (Jiménez Ávila, 2016: 84; Torres, 2017: 376), pues se desconoce el poblado o asentamiento al que estarían vinculadas. Mientras, la necrópolis de El Pozo siempre ha estado relacionada con la posible existencia de un poblado en altura ubicado en el Cerro del Castillo de Medellín (Almagro-Gorbea, 1977, 2008), la elevación más próxima a este espacio funerario. Sin embargo, la arqueología todavía no ha sido capaz de

Ediciones Universidad de Salamanca / 요 corroborar la existencia de tal poblado, pues, a pesar de la destacada actividad arqueológica desarrollada en las laderas del Cerro del Castillo desde los años 70 del pasado siglo hasta nuestros días, siguen sin documentarse estructuras que permitan certificar la existencia de un poblado fechado en la I Edad del Hierro - una revisión de las secuencias estratigráficas del Cerro del Castillo en Rodríguez González, 2018-. Frente a ello, todas las evidencias, tanto materiales como territoriales, parecen apuntar que el asentamiento debió localizarse al sur del cerro, bajo el actual municipio de Medellín (Celestino, 2005: 771; Rodríguez González, 2018: 106).

\section{El paisaje funerario del Guadiana Medio durante la I Edad del Hierro}

El análisis topográfico de la necrópolis de El Pozo permitió concluir que ocupaba una

... franja de terreno que formaba una pequeña elevación sobre la zona circundante, casi imperceptible a simple vista, ya que apenas destaca $1 \mathrm{~m}$ sobre el entorno. Esta zona, de aproximadamente 1 ha de extensión, debió quedar situada en la antigüedad entre dos brazos que partían hacia el sur desde el cauce actual del Guadiana, situado a unos $200 \mathrm{~m}$ al norte [...] Ambos cauces están actualmente enrunados y apenas visibles, ya que en la actualidad solo resurgen en las grandes crecidas, como las ocurridas en 1969 y 1979, que permitieron constatar el carácter cuasi-isleńo del terreno que ocupa la necrópolis, zona que, en la Antigüedad, debía quedar dentro del cauce inundable por las avenidas habituales del río Guadiana... (Almagro-Gorbea, 2008b: 894)

A pesar de que siempre han existido indicios acerca de la relación entre el Guadiana y uno de sus brazos con la necrópolis de El Pozo, que en ocasiones se ha visto inundada por las crecidas de los cauces antes mencionados, nunca se ha emprendido un estudio geográfico que permita corroborar este hecho. Tampoco se ha analizado la topografía correspondiente a las necrópolis de Valdelagrulla y Aljucén, dejando al margen el caso de Mengabril, cuya localización nos resulta, lamentablemente,

Zephyrus, LXXXVIII, julio-diciembre 2021, 87-110 
desconocida, para determinar si ambos ejemplos poseen una relación directa con cursos de agua hoy desaparecidos. Así mismo, nunca se ha efectuado un trabajo comparativo que permita definir la relación que existe entre las necrópolis del Guadiana Medio con otras manifestaciones funerarias del so peninsular, un estudio que, en definitiva, nos habría permitido considerar la existencia de un patrón, tanto a nivel territorial como simbólico, en la elección del espacio destinado a la ubicación de las necrópolis durante la I Edad del Hierro.

De ese modo, con el objetivo de precisar el espacio ocupado por estas necrópolis y determinar la naturaleza de sus entornos hemos emprendido el análisis del paleopaisaje y la detección de paleocauces, tanto del Guadiana como de sus principales afluentes, a partir de la combinación de diferentes datos espaciales y el empleo de un modelo metodológico que, con ciertas variaciones y objetivos muy distintos, ya ha sido puesto en práctica en otras regiones peninsulares (Monterroso-Checa, 2019).

El punto de partida es la localización territorial de los tres casos de estudio, ubicados junto al río Guadiana, próximos a la confluencia entre este y uno de sus principales afluentes. Como ya indicábamos en la introducción, el paisaje de las Vegas del Guadiana se ha visto transformado en las últimas décadas como consecuencia de la puesta en práctica de una agricultura extensiva de regadío. Al mismo tiempo, el Guadiana se ha convertido en un río controlado cuyo cauce está gestionado por la presencia de varios embalses que regulan su escorrentía, por lo que ni su anchura ni su regularidad responden al patrón que tendría en la Antigüedad.

Para emprender el estudio de la topografía en la que se insertan las necrópolis y los cursos de agua hoy canalizados, amortizados o desaparecidos, hemos recurrido al uso de diversas fuentes de información. Por un lado, las series de fotografías históricas del Vuelo Americano, tanto la Serie A -1945-1946como la Serie в -1956-1957-, de gran importancia al permitirnos un acercamiento a la organización del territorio previa a la reparcelación y transformación a la que ya hemos aludido. Dicha transformación puede comprobarse al comparar los fotogramas

Ediciones Universidad de Salamanca / 요요 históricos con las ortofotografías del PNOA de máxima actualidad empleadas también en este estudio. Por otro lado, ha sido fundamental el uso de Modelos Digitales del Terreno-MDT-, cuya resolución ha aumentado notablemente en los últimos años gracias a la liberación de datos brutos de los vuelos Lidar del Plan Nacional de Ortofotografía Aérea -PNOA- con la resolución de 0,5 puntos $/ \mathrm{m}^{2}$ por parte del Centro Nacional de Información Geográfica-CNIG-, así como por la creación de capas ráster de $2 \mathrm{~m}$ de resolución-MDT02-, proporcionadas por esta misma institución ${ }^{3}$.

La primera fase del análisis ha comprendido el trabajo de observación de las Series del Vuelo Americano con el objetivo de detectar antiguos cursos de agua hoy amortizados por la construcción de acequias o coladas de agua y ocupados tanto por construcciones como por campos de labor. Su comparativa con las fotografías áreas de máxima actualidad facilitadas por el PNOA nos permitió aportar una hipótesis de trabajo: la posibilidad de que la parcela sobre la que se localizan los tres casos de estudio hubiese estado rodeada de agua en la Antigüedad, convirtiendo el territorio en el que se localizan las necrópolis en auténticas islas o penínsulas.

Para corroborar esta hipótesis hemos empleado una metodología de trabajo novedosa basada en la combinación de los Modelos Digitales del Terreno, una vez reclasificados para mejorar su visualización, y la información recopilada por la Confederación Hidrográfica del Guadiana - CHG- acerca de las Áreas de Riesgo Potencial Significativo de Inundación -ARPSI- con cuyos datos podemos valorar la cota de calado esperable en caso de inundación (Rodríguez González et al., 2021). Para ello se han empleado tres períodos de retorno: T10, т100 о т500, lo que se traduce en la existencia de eventos que potencialmente sucederían una vez cada 10, 100 o 500 años. Según la información emitida por la CHG, las

3 Toda la información cartográfica empleada en este estudio ha sido descargada del Centro de Descargas del CNIG, a excepción de la Serie a del Vuelo Americano que procede del Sistema de Información Territorial de Extremadura -SITEX-. Ambas plataformas son de acceso libre y gratuito. 
primeras evidencias de crecidas del río registradas se fechan en el 620; sin embargo, la recogida sistemática de las mismas se inicia en 1935. En este sentido, somos conscientes de la contemporaneidad de los datos y la complejidad que puede suponer su extrapolación a un escenario del pasado, pero también es cierto que se trata del conjunto de datos que mejor nos traslada a la realidad hidrográfica de un río trasformado cuyo cauce original será difícil de recuperar, permitiéndonos así acercarnos con exactitud a la paleogeografía del Guadiana y sus afluentes, así como a las causas que llevaron a las sociedades de la I Edad del Hierro de este territorio a elegir estos puntos para la localización de sus necrópolis.

Para la visualización de cada uno de los ejemplos y de los datos anteriormente desglosados, hemos fusionado dos modelos. Así, sobre el MDT de $2 \mathrm{~m}$ empleado como base cartográfica hemos realizado un sombreado - hillshade- desde una única dirección -Azimuth 315, Altitude 45- con el objetivo de favorecer la visualización del relieve. Sobre este modelo hemos superpuesto el MDT reclasificado a partir de los datos del ARPSI, aplicándole un $35 \%$ de transparencia para apreciar la topografía, para finalmente generar el modelo definitivo.

Para favorecer la comprensión de los datos, teniendo en cuenta la naturaleza de cada uno de los casos de estudio, expondremos a continuación el proceso realizado y los datos empleados en cada uno de los yacimientos, para proceder, posteriormente, a emitir una valoración conjunta de los resultados obtenidos.

\subsection{La necrópolis de El Pozo (Medellín, Badajoz)}

La necrópolis de El Pozo se localiza en la orilla izquierda del Guadiana, a algo más de $500 \mathrm{~m}$ al oeste del actual municipio de Medellín y a $1 \mathrm{~km}$ de la desembocadura del río Ortigas, uno de sus principales afluentes. La consulta del mapa geológico del IGME (2008) ya permite distinguir la existencia de al menos dos brazos del río, hoy colmatados, que separan esta parcela ocupada por la necrópolis del actual enclave de Medellín, lo que convierte este

Ediciones Universidad de Salamanca / 용 espacio en una pequeña isla (Fig. 4a). Estos canales abandonados del Guadiana y el terreno emergido sobre el que se situó la necrópolis se pueden distinguir perfectamente en varias de las series de fotografías históricas disponibles, como es el caso de la Serie a del Vuelo Americano (Fig. 4b), donde puede observarse con claridad la existencia de una pequeña isla que debió alcanzar las $12-13$ ha de extensión.

La incorporación de los datos del ARPSI de la CHG sobre el MDT02 nos ha permitido generar un modelo en el que se distingue la situación de esta isla ante los diferentes eventos de inundación previstos (Fig. 5), observando como la necrópolis se vería afectada por las crecidas del Guadiana, quedando emergida en los eventos т10 у т 100 y sumergida en los eventos $\mathrm{T} 500$, donde su cota no sería lo suficientemente elevada para salvaguardarse de las inundaciones. La existencia de estas crecidas queda atestiguada por los Estratos II y III documentados durante las labores de excavación de la necrópolis (Almagro-Gorbea, 2006c: 36). Así, mientras el Estrato II alcanzaba una media de espesor de 0,25 $\mathrm{cm}$ que fue puesta en relación con la crecida que el río experimentó entre 1940 y 1941 que inundó toda esta área; el Estrato III, formado también por un limo pardo, cuenta con áreas en las que alcanza los $2 \mathrm{~m}$ de espesor, cubriendo todo el espacio de la necrópolis excavada. Esta potencia posiblemente se deba a las crecidas que han afectado al área en la que se localiza la necrópolis desde su abandono en el s. va. C.

Pero la consulta del modelo final generado tras la combinación del MDT y los datos de inundación deja al descubierto un detalle más sobre la ocupación del territorio de Medellín. En el segundo epígrafe de este trabajo ya hemos hecho alusión a la falta de evidencias que certifiquen la existencia de un poblado en altura que ocupe las laderas del Cerro del Castillo de Medellín, a pesar de la multitud de intervenciones arqueológicas realizadas con tal fin. Frente a ello, hemos vuelto a valorar nuestra hipótesis acerca de la posible localización del poblado a los pies de la ladera sur (Rodríguez González, 2018: 106, fig. 43), bajo el actual municipio 

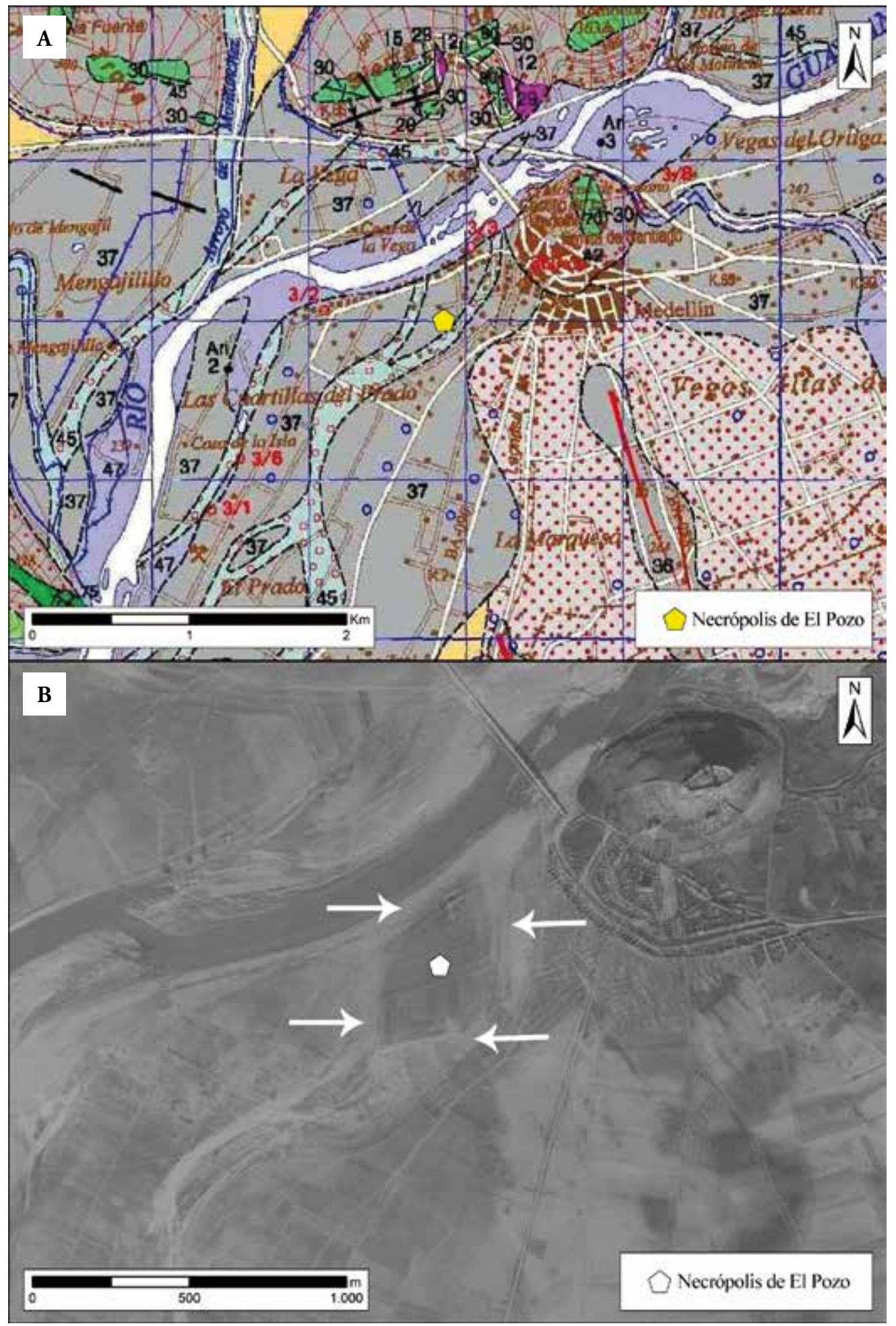

Fig. 4. Necrópolis de El Pozo, Medellin, Badajoz: A. Ubicación en el mapa geológico nacional (IGME, hoja 778); B. Fotograma del Vuelo Americano A (1945); en ambas imágenes se aprecia la silueta de la isla en la que se localiza la necrópolis. 


\section{y la reconstrucción del paleopaisaje funerario de las necrópolis tartésicas}

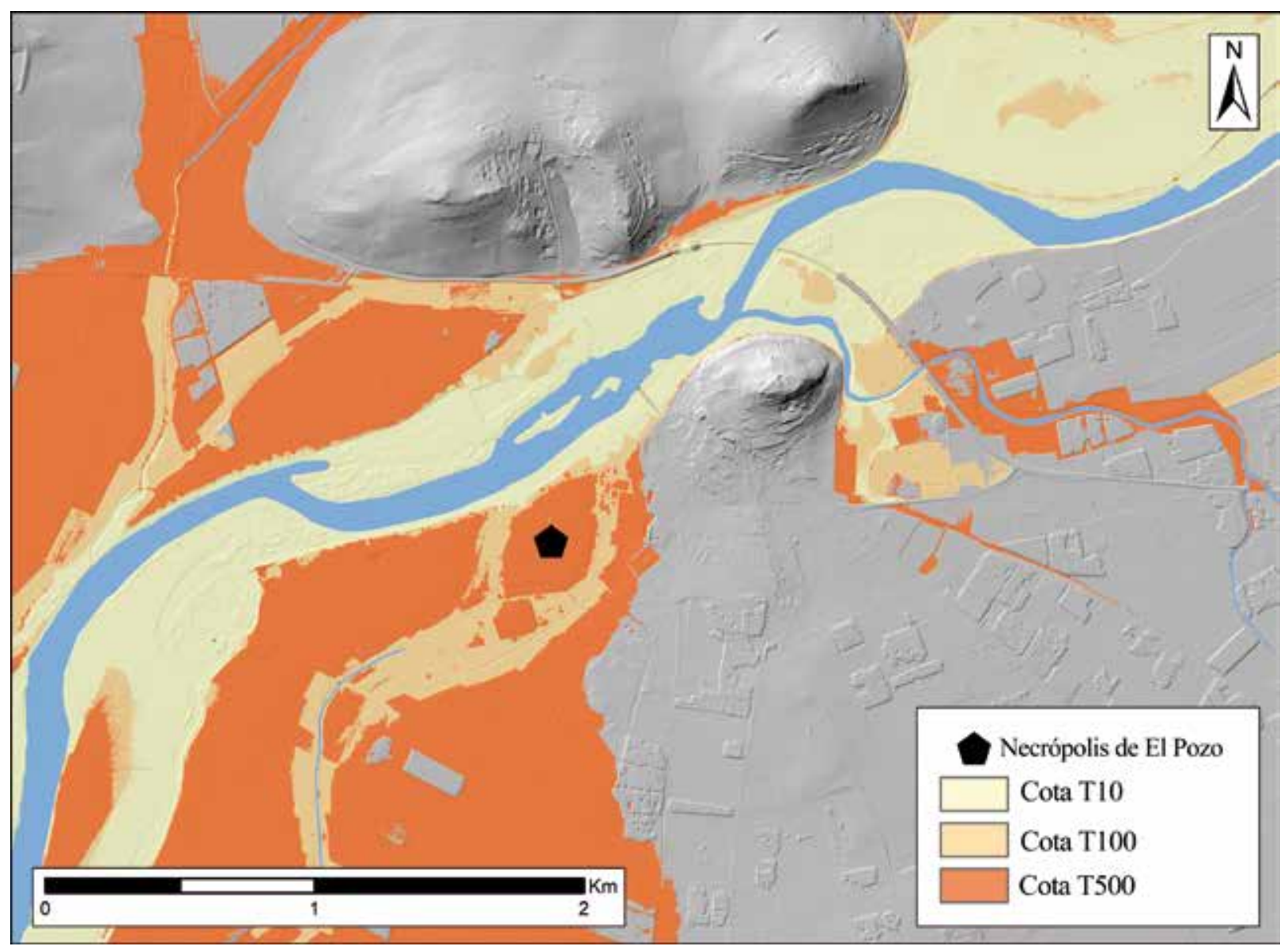

Fig. 5. Localización de la necrópolis de El Pozo, Medellín, Badajoz, sobre MDTO2 del CNIG modificado con los datos ARPSI de la CHG.

de Medellín. Como puede observarse en el modelo generado para este estudio, esta área quedaría salvaguardada de las frecuentes crecidas del Guadiana, incluso de los eventos $\mathrm{T} 500$, lo que suma un argumento más para confirmar la ubicación del poblado de la i Edad del Hierro, que se situaría en el llano y a salvo de las crecidas del Guadiana.

\subsection{La necrópolis de Valdelagrulla (Medellin, Badajoz)}

Se ubica a $3 \mathrm{~km}$ del cauce del Guadiana y a unos $700 \mathrm{~m}$ del actual cauce del Ortigas, encontrándose a poco más de $1,5 \mathrm{~km}$ al No del actual municipio de Medellín. El estudio del territorio que rodea esta necrópolis es el mejor ejemplo para evaluar el grado de transformación que han sufrido las vegas del Guadiana desde los años 50 del pasado siglo y el impacto que la agricultura actual genera en el paisaje.

En la actualidad, ningún curso de agua separa la hipotética localización del poblado protohistórico de Medellín de la necrópolis de Valdelagrulla; sin embargo, el análisis de la fotografía histórica muestra la existencia de un antiguo brazo del río Ortigas que se unía al trazado principal a la altura de su desembocadura en el Guadiana y nacía en el propio Ortigas, al $\mathrm{N}$ de la localidad de Mengabril (Fig. 6). Dicho cauce es ahora imposible de detectar en los trabajos de campo dado que la depresión que lo formaba ha sido colmatada de tierra y actualmente 
se encuentra ocupada por terrenos dedicados al cultivo de frutales y al regadío.

La Serie в del Vuelo Americano nos muestra con claridad cómo este paleocauce del río Ortigas pasaba al oeste de la necrópolis (Fig. 7a), un brazo del río que, si bien hoy está perdido, todavía puede rastrearse en distintos fotogramas posteriores, como el Interministerial de los ańos 70, el olistat de los años 90 o el PNOA de máxima actualidad donde la línea del antiguo trazado del río genera un crecimiento diferencial de la vegetación como puede apreciarse con claridad en el análisis de la fotografía aérea (Fig. 7b-d). En este caso, las profundas modificaciones del terreno, que incluyen aportes de tierra para la nivelación de las zonas de cultivo, nos impiden emplear los datos procedentes de la combinación de los ARSPI y los modelos LiDAR para reconstruir el paleopaisaje y estudiar las áreas afectadas por las inundaciones, ya que las llanuras de inundación del antiguo brazo se han perdido. No obstante, solo el análisis de la fotografía aérea nos permite determinar cómo la necrópolis de Valdelagrulla también se localizaba separada del núcleo de población más cercano, el poblado protohistórico de Medellín, por un cauce de agua secundario del río Ortigas.

\subsection{La necrópolis de Aljucén (Mérida, Badajoz)}

El caso de Aljucén es igualmente significativo. La necrópolis se localiza en un promontorio

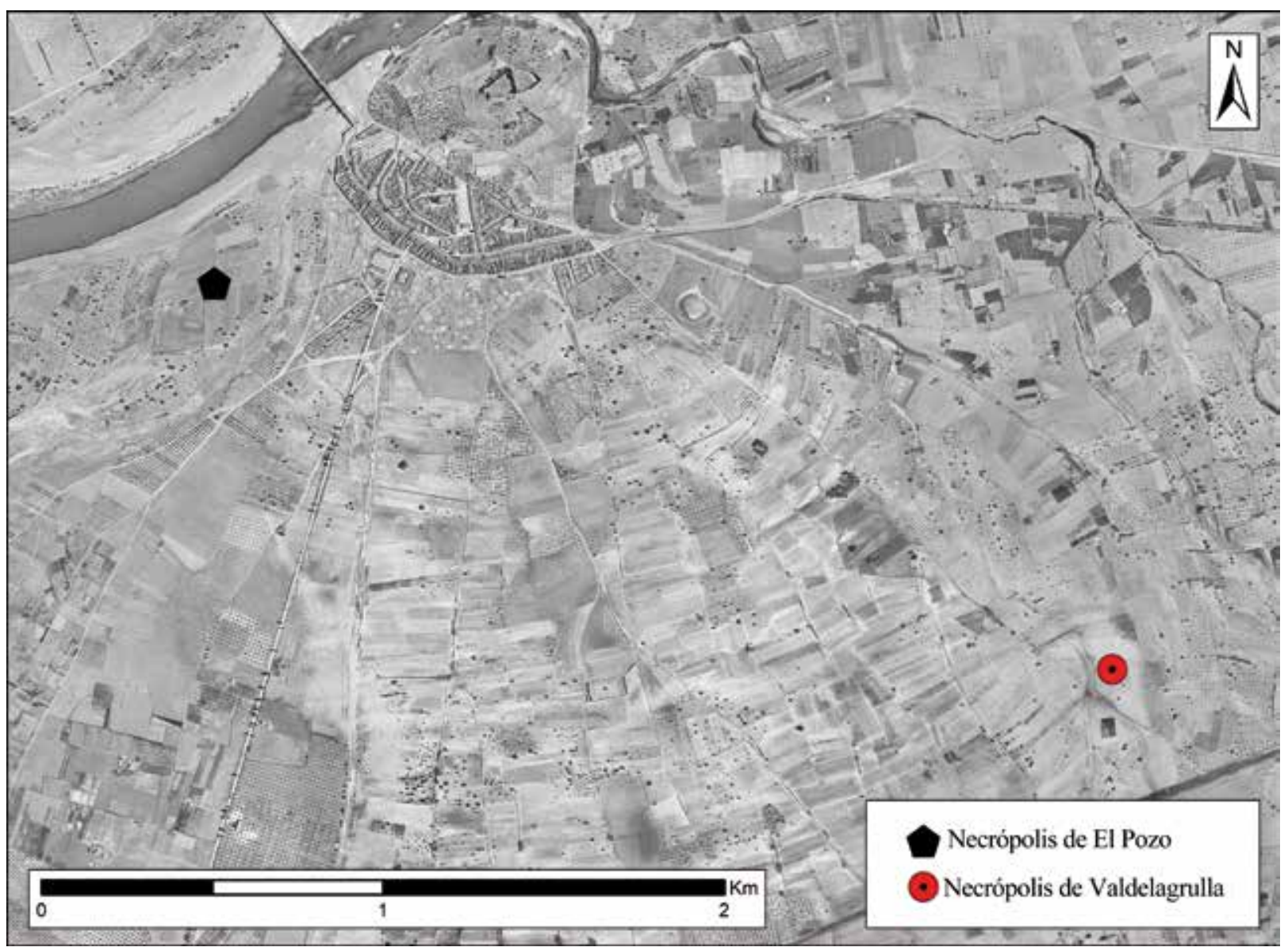

Fig. 6. Localización de la necrópolis de Valdelagrulla, Medellín, Badajoz, con respecto a los ríos Ortigas y Guadiana, asi como al cerro del Castillo de Medellín y la necrópolis de El Pozo, Medellin, Badajoz. 


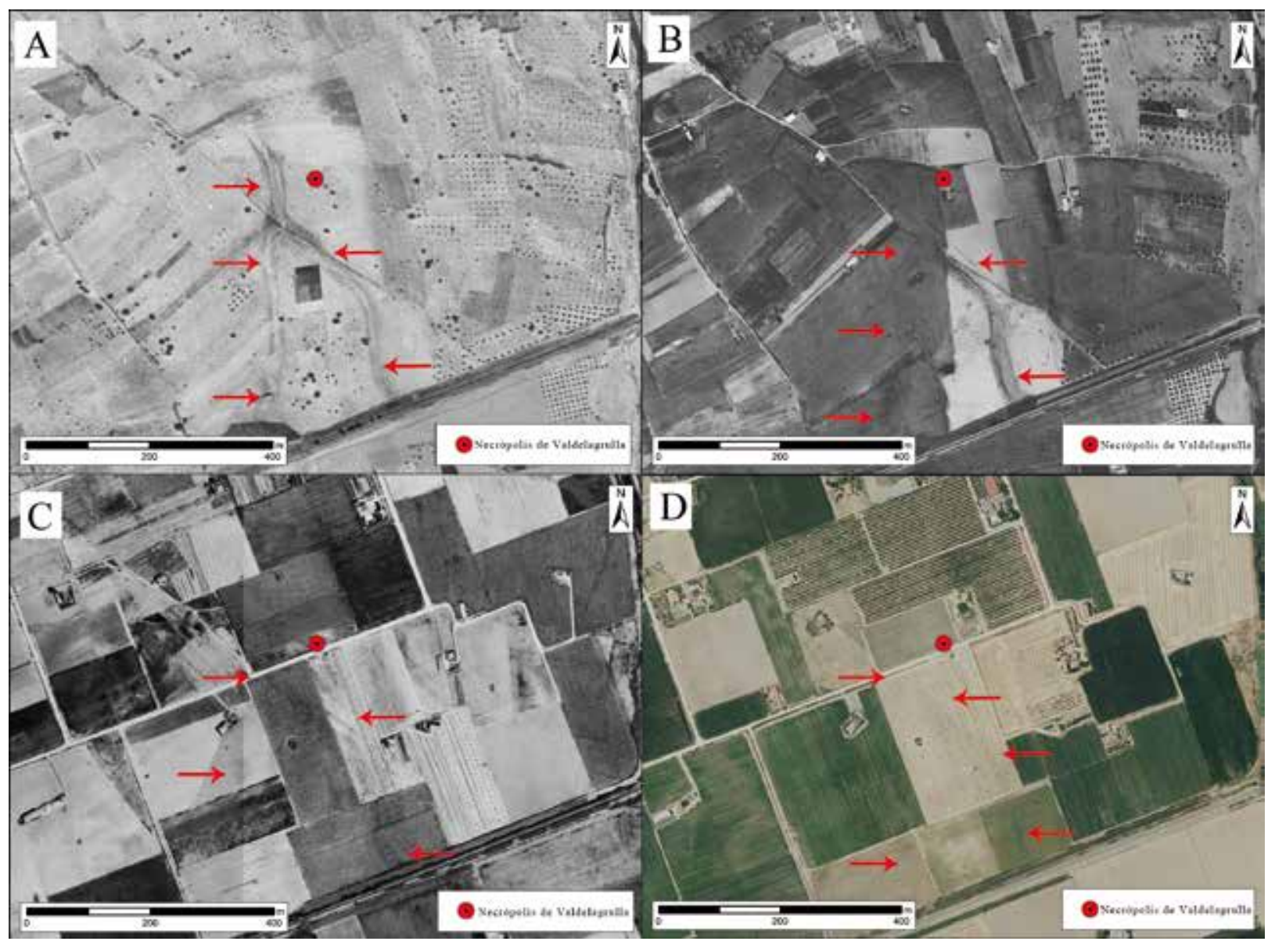

Fig. 7. A) Fotograma del Vuelo Americano B (1956-1957); B) fotograma del Vuelo Interministerial, 1973; C) fotograma del satélite Olistat, 1997-1998; D) ortofotografía del PNOA máxima actualidad. En todas ellas aparece ubicada la necrópolis de Valdelagrulla, Medellin, Badajoz, y señalizado el trazado del paleocauce del rio Ortigas hoy desaparecido. La progresión de los fotogramas permite observar como el cauce ha ido colmatándose hasta su desaparición. Actualmente solo puede detectarse a partir del crecimiento diferencial de la vegetación.

conformado por el horcajo de los ríos Guadiana y Aljucén, así como por una vaguada que discurre paralela al primero de ellos (Fig. 8). La construcción del embalse de Montijo en 1954 no permite realizar una comparativa entre la Series de Fotogramas del Vuelo Americano y la localización actual de la necrópolis, a los pies de la orilla del embalse, al encontrarse una buena parte de la porción de tierra que quedaba entre los ríos Guadiana y Aljucén sumergida bajo sus aguas.

Sin embargo, la combinación de los datos del MDT02 y el nivel de crecida estimado en períodos de inundación proporcionados por la CHG permite observar sobre el modelo generado aquellos terrenos que se verían afectados en los períodos de retorno т10, т100 у т500 (Fig. 9). En este caso, la topografía del terreno provoca que las crecidas del Guadiana se orienten al sur, siendo la afección de la ribera septentrional menos pronunciada. De igual forma, el aumento del nivel del agua modificaría escasamente la orilla izquierda del río Aljucén; sin embargo, son los cauces del regato estacional, situado al este de la necrópolis, y la llanura de inundación de la confluencia con el arroyo de la Albuera los que se verían afectados por las crecidas, generando que el espacio en el que se localiza la necrópolis se 


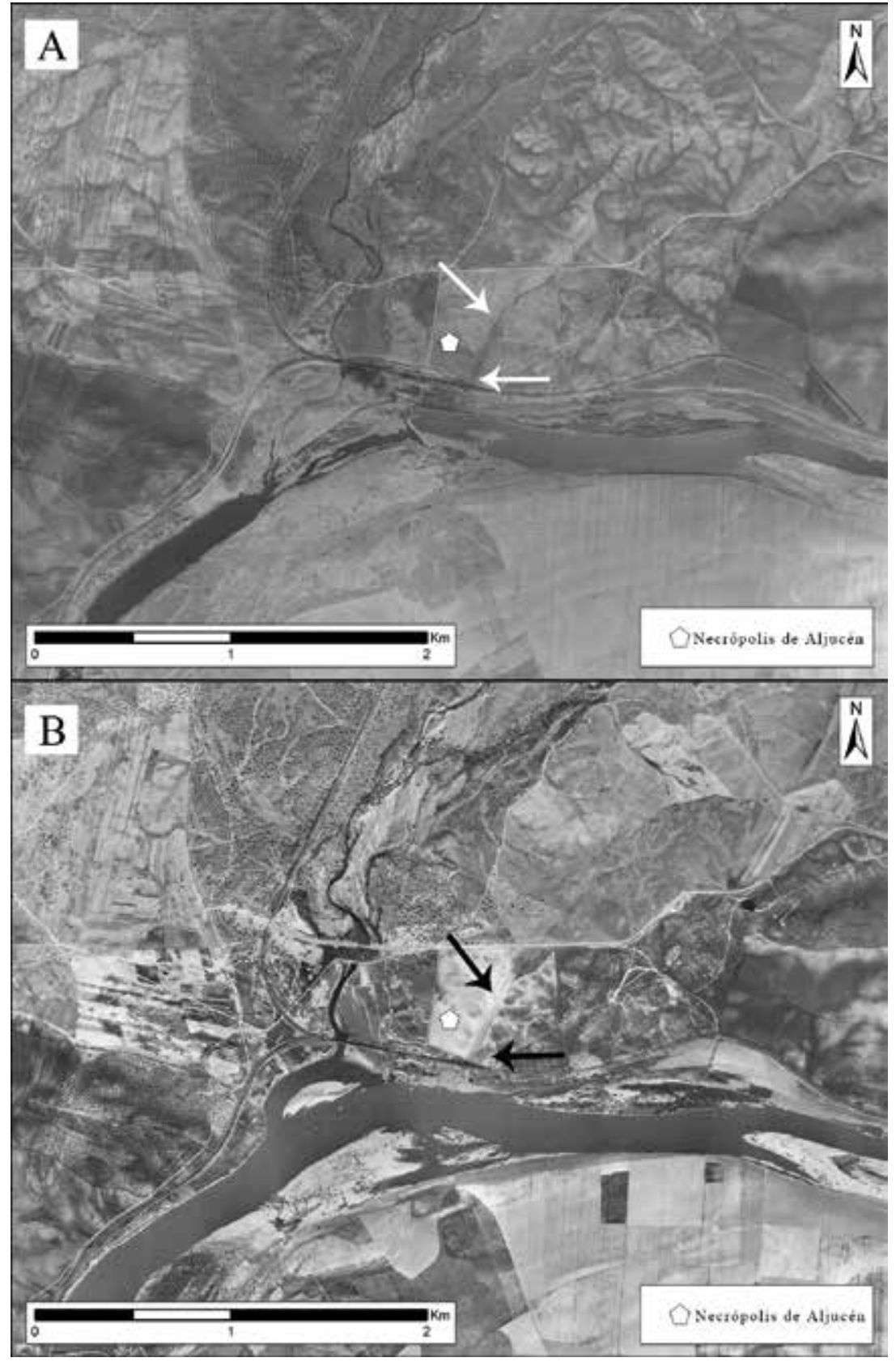

FIG. 8. A) Fotograma del Vuelo Americano A, 1945; B) fotograma del Vuelo Americano B, 1956-1957; en ambas imágenes se ha ubicado la necrópolis del Aljucén (Mérida, Badajoz) y ha sido indicado el paleocauce de uno de los afluentes del Guadiana que rodeaba el espacio de la necrópolis en la Antigüedad. los diferentes eventos de crecida que afectan al río Guadiana.

En cuanto a la posición de la necrópolis de Aljucén con respecto a su posible conexión con un poblado, cabe indicar que tenemos una referencia que alude a la "... posible existencia de un castro de la Edad del Hierro junto a la desembocadura del río Aljucén...” (Álvarez Martínez, 1984: 104). Durante las labores de excavación de la necrópolis se procedió a la prospección del entorno sin que pudieran localizarse más restos de la I Edad del Hierro (Enríquez y Domínguez de la Concha, 1991: 36), lo que nos lleva a suponer que el lugar aludido anteriormente se encuentre al otro lado del punto elegido para la ubicación de la necrópolis. En este sentido cabe señalar que en la otra orilla del río Aljucén, frente al punto que actualmente ocupa la necrópolis, se localiza el túmulo del Tiriñuelo, de unos $50 \mathrm{~m}$ de diámetro. El análisis del túmulo procede, únicamente, de la fotografía aérea y de algunos materiales recuperados de la parte baja del cerro (Rodríguez Díaz et al., 2004: 609), pues los dueños de la parcela en la que se localiza la elevación siempre han mostrado su negativa ante la idea de realizar trabajos arqueológicos en la misma. Sin embargo, la consulta del modelo generado a partir de la implementación de los datos correspondientes a los convirtiese en una península con un estrecho corredor que la conectaría con las áreas no inundables; así, la necrópolis estaría emergida y al resguardo de niveles de inundación muestra un detalle de gran interés, pues el espacio ocupado por el túmulo y el territorio circundante quedan fuera de las áreas 


\section{y la reconstrucción del paleopaisaje funerario de las necrópolis tartésicas}

afectadas por los períodos de retorno. Por lo tanto, se trata de un terreno que a pesar de su proximidad al río Guadiana estaría al resguardo de sus crecidas, al mismo tiempo que dispondría de las tierras fértiles que estas inundaciones generarían a su paso.

\section{Discusión}

La combinación de la información arqueológica, fotográfica y cartográfica nos ha permitido confirmar la existencia de una intencionalidad en el ejercicio de seleccionar los espacios para la deposición de los difuntos. Así, las necrópolis de la I Edad del Hierro del valle medio del Guadiana ocupan áreas que en la Antigüedad se encontraban rodeadas de agua, si no de forma permanente, al menos durante períodos concretos, lo que permitía el aislamiento de los espacios funerarios y su separación de las áreas de población cercanas.

Rastrear el origen de este patrón de asentamiento es una tarea compleja a tenor de los escasos estudios territoriales realizados en torno a las necrópolis

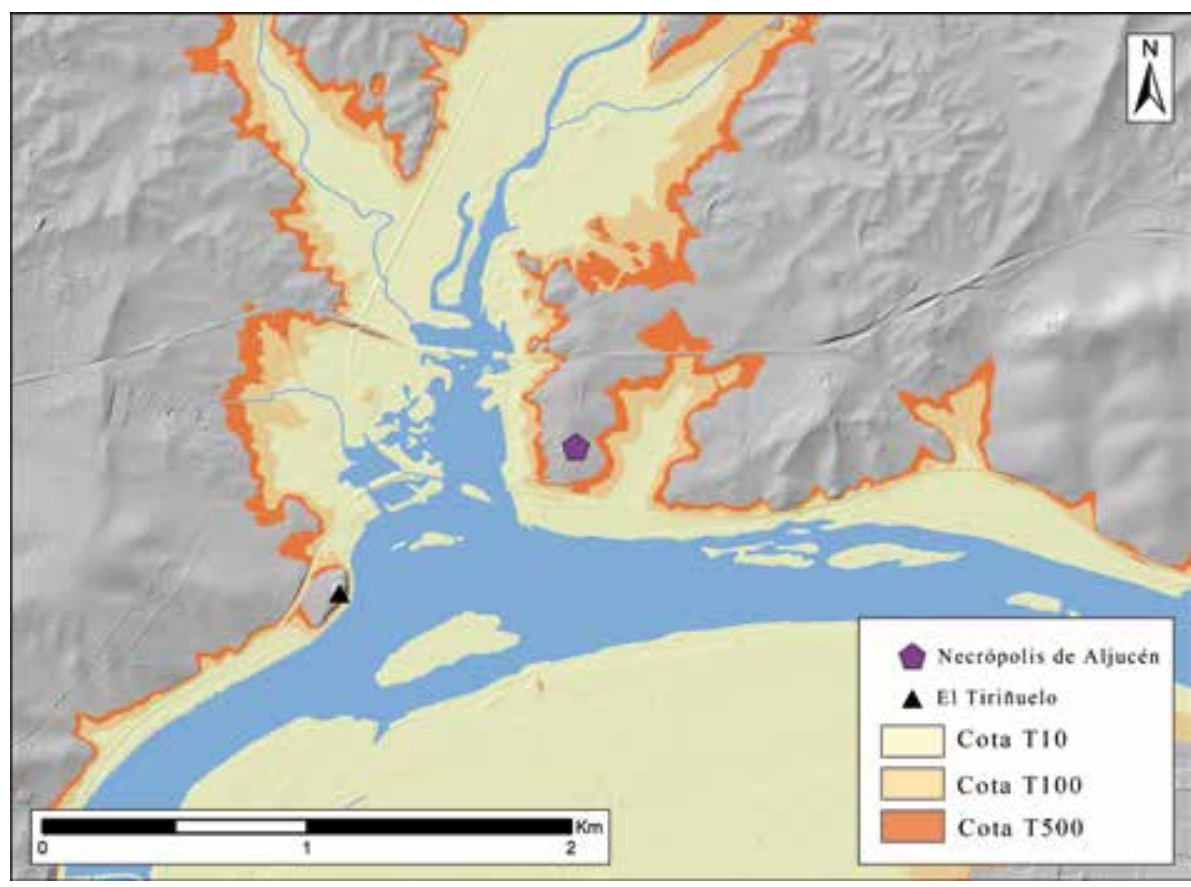

Fig. 9. Localización de la necrópolis de Aljucén (Mérida, Badajoz) sobre MDTO2 del CNIG modificado con los datos ARPSI de la CHG. protohistóricas del Mediterráneo Occidental. Sin embargo, al igual que muchos otros elementos presentes en las necrópolis tartésicas poseen una clara filiación oriental, caso de los marfiles documentados en los ajuares o las urnas tipo 'Cruz del Negro' empleadas como contenedores de los restos cremados del difunto, la norma de separar ambos espacios, poblados y necrópolis, por un curso de agua, procede del mundo fenicio. Así, esta tradición ha sido detectada en ejemplos tan significativos como la ciudad de Tiro, donde la necrópolis de Al Bass estaba, en origen, ubicada en la orilla opuesta a la isla de Tiro, separada del asentamiento por el río Ras el-Ain (Aubet, 1987: 259; Aubet et al., 2004; Frendo et al., 2005: 428).

Esta pauta se emula posteriormente en las colonias fenicias de occidente, donde está ampliamente constatado que los poblados fundados en las desembocaduras de los ríos se encuentran separados de las áreas de necrópolis por un cauce fluvial o canal (Pellicer, 2004: 13-14; De Jonghe, 2017: 60). Este es el caso de las necrópolis de Laurita y Puente de Noy, separadas de la colonia de Sex por el río Seco; de la necrópolis de $\mathrm{El}$ Campillo, separada de la colonia de Abdera por el río grande de Adra; de la necrópolis de Cerro del Mar, separada de Toscanos por el río Vélez; de la necrópolis de Montánchez, separada del Cerro del Villar por el río Guadalhorce; o de la necrópolis de Trayamar, separada de la colonia de Morro de Mezquitilla por el río Algarrobo (Frendo et al., 2005: 429-430, fig. 3). No obstante, hay que reconocer la existencia de dos ejemplos que no cumplen este patrón a partir de los cuales se confirma la regla. Se trata de las 
necrópolis de Jardín, próxima a la colonia de Toscanos, y del Cerro de la Velilla, en Almuñécar. La inexistencia de un elemento natural que separe ambas necrópolis de sus poblados ha sido explicada a nivel cronológico, indicando cómo estos espacios de enterramiento parecen coincidir con la fase final de ocupación de los poblados, de ahí la pérdida del patrón de separación entre ambas áreas (De Jonghe, 2017: 60).

La separación entre la necrópolis y el poblado también se registra en el Castillo de Doña Blanca (Ruiz Mata y Pérez, 1995), cuya necrópolis se localiza en la falda de la sierra de San Cristóbal, al norte del poblado, y sus túmulos se distribuyen por pequeñas elevaciones que se encuentran rodeadas por escorrentías y cauces de agua (Ruiz Mata y Pérez, 1995: 176-177). También se define para el caso de Ayamonte, Huelva, cuya necrópolis está separada del Barrio de la Villa, cerro en el que se localiza el hábitat fenicio, por el cauce del arroyo de la Noria (García et al., 2016: 498-499). Así, aunque algunos autores hayan considerado que dicho patrón no puede ser considerado absoluto ante la presencia de dos casos de estudio que se salen de la pauta (De Jonghe, 2017: 67), lo cierto es que el elevado número de ejemplos en los que se detecta esta separación nos permite confirmar la perduración de una práctica cuyo origen puede situarse en el Levante del Mediterráneo (Gras et al., 1991: 166). La detección de este patrón ha llevado a algunos investigadores a considerar la existencia de una 'geografía funeraria fenicia' que puede ponerse en relación con el viaje al Más Allá realizado por el difunto, donde el agua tendría un papel fundamental. Este hecho tendría una relación directa con la escatología cananea y egipcia, emulada posteriormente por los fenicios en otras regiones del Mediterráneo (Frendo et al., 2005: 429). De ese modo, y como aquí venimos defendiendo, la elección del lugar para la ubicación de las necrópolis no obedecería a una cuestión funcional, sino ritual.

A pesar de las similitudes que comparten las necrópolis de las colonias fenicias occidentales con las necrópolis tartésicas del s peninsular como se ha señalado con anterioridad, nunca se ha emprendido

Ediciones Universidad de Salamanca / 요 un estudio territorial de estas últimas que analice el paisaje en el que se ubican con el objetivo de detectar la reproducción de este patrón en enclaves como La Joya, Huelva; Mesas de Hasta, en Jerez de la Frontera, Cádiz; El Bencarrón, en Alcalá de Guadaira, Sevilla; El Acebuchal, en Carmona, Sevilla; La Cruz del Negro, en Carmona, Sevilla; o la Cañada de Ruiz Sánchez, en Carmona, Sevilla, por citar algunos de los enclaves mejor conocidos.

El primer trabajo que ha incorporado un estudio geoarqueológico que ha permitido detectar la existencia de un curso de agua, hoy inexistente, pero que en la Antigüedad se encargó de separar el poblado de la necrópolis, es La Angorrilla, en Alcalá del Río, Sevilla. Esta necrópolis se ubica a unos $800 \mathrm{~m}$ al so del poblado y está separada del mismo por una vaguada que tiempo atrás estaba ocupada por el arroyo estacional Cagancha, que desemboca en el Guadalquivir (Fernández Flores et al., 2014: 27). La revisión de la bibliografía nos ha permitido incorporar un caso de estudio más, la necrópolis de Setefilla, en Lora del Río, Sevilla, donde la Mesa de Setefilla, elevación en la que se sitúa el poblado, todavía hoy está separada del espacio de necrópolis por el arroyo del Pilar, el cual desemboca en el río Guadalbacar en las proximidades de esta (Ruiz Delgado, 1983: 16, fig. 2).

Junto a estos dos ejemplos, donde la separación es clara, existen otros indicios que a falta de un estudio geomorfológico que lo corrobore parecen también cumplir este patrón. Es el caso de la relación entre el poblado tartésico de Caura, en Coria del Río, Sevilla, localizado sobre el Cerro de San Juan y una posible necrópolis que, a falta de unos trabajos arqueológicos que certifiquen la existencia de la misma en este punto, tradicionalmente se ha ubicado en el cercano Cerro de Cantalobos (Gómez Peña, 2018: 189-190); o las necrópolis que ocupan las elevaciones de los Alcores, actualmente separadas de sus núcleos de poblamiento por la existencia de un conjunto de arroyos que bordean cada una de las elevaciones. Todos estos indicios, todavía por analizar, otorgan a este territorio un gran interés para emprender un estudio de estas características y

Zephyrus, LXXXVIII, julio-diciembre 2021, 87-110 


\section{y la reconstrucción del paleopaisaje funerario de las necrópolis tartésicas}

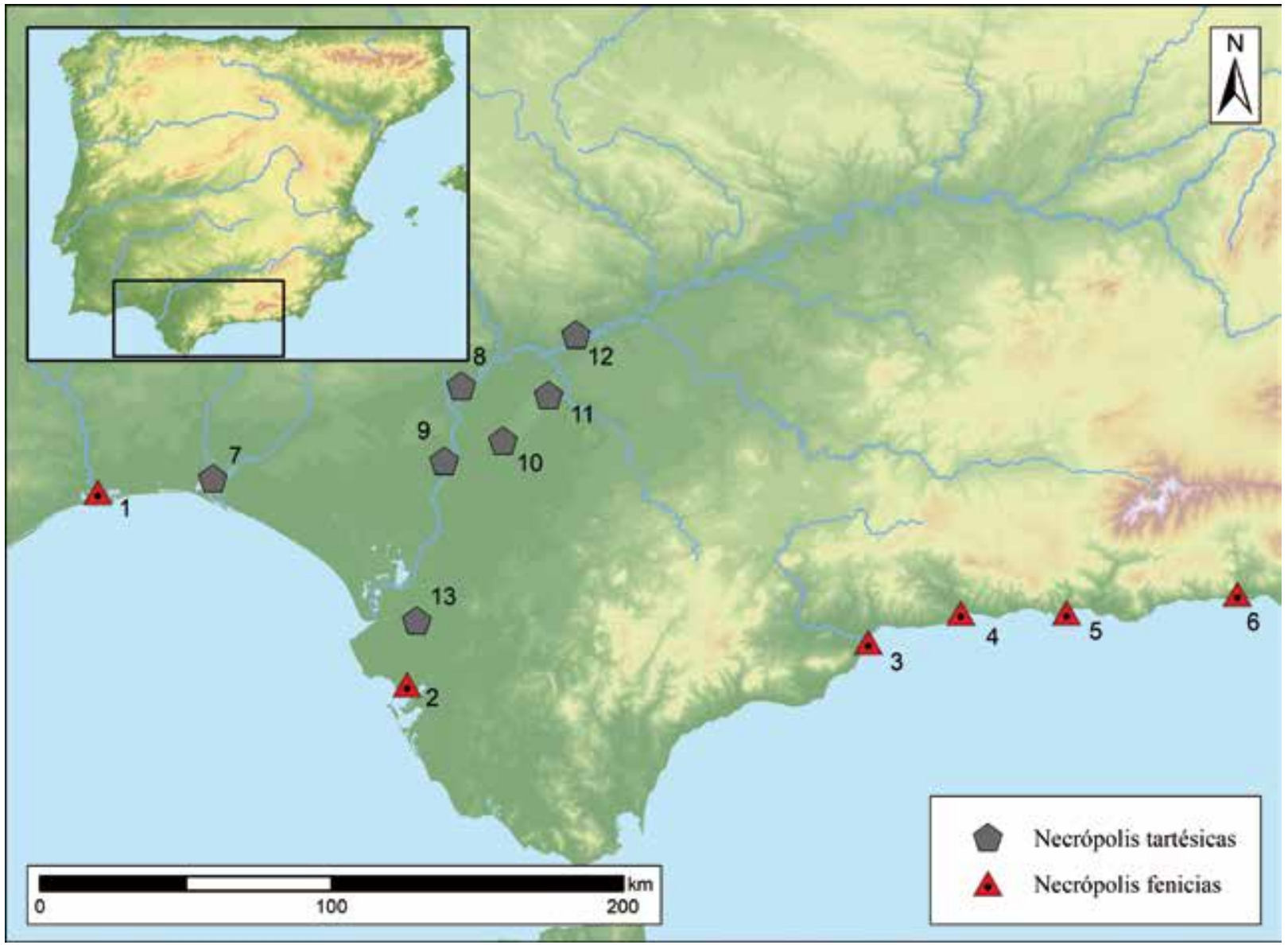

FIG. 10. Localización de las necrópolisfenicias y tartésicas del so peninsular: 1. Ayamonte; 2. Castillo de Doña Blanca; 3. Montánchez; 4. Trayamar-Jardin; 5. Laurita-Puente de Noy-Cerro de la Velilla; 6. El Campillo; 7. La Joya; 8. La Angorrilla; 9. Cerro de Cantalobos; 10. El Bencarrón; 11. Acebuchal-Cruz del Negro-Cañada de Ruiz Sánchez; 12. Setefilla; 13. Mesas de Asta (elaborado sobre MDT de 25 m de resolución del Servicio Global de Tierras de Copernicus-CGLS).

definir la relación que existe entre los cursos de agua $\mathrm{y}$, posteriormente, entre las necrópolis y los poblados; ahora que los análisis efectuados en las necrópolis del valle medio del Guadiana han permitido corroborar la perduración de este patrón hasta el s. v a. C.

\section{Conclusiones}

En la introducción de este trabajo planteábamos una serie de interrogantes que giran en torno al análisis espacial y paisajístico de las necrópolis tartésicas del so peninsular. En ellas cuestionábamos el papel que juega el paisaje en la localización de los enterramientos y el significado de la ubicación que estos espacios funerarios presentan en el territorio, así como la existencia de un patrón en la elección de los espacios y la posibilidad de que las tradiciones de una sociedad queden plasmadas en la elección del lugar de deposición de sus difuntos.

La metodología propuesta y aplicada en este trabajo al espacio ocupado por las necrópolis tartésicas del valle medio del Guadiana nos permite, por el momento, responder con claridad a las dos primeras, pues la combinación de los datos espaciales y arqueológicos ha permitido considerar la importancia que tiene el paisaje en la elección de los espacios para la ubicación de las necrópolis, un hecho que 
ya estaba ampliamente constatado en el caso de los asentamientos o poblados, donde los estudios territoriales son más abundantes.

Esta evidencia nos permite sacar una doble conclusión; por un lado, una lectura territorial y, por otro lado, una apreciación sobre el significado simbólico que la ubicación de las necrópolis presenta. Aunque esta última idea no forma parte de los objetivos de nuestro trabajo, el patrón detectado nos lleva a realizar una pequeña reflexión que en este sentido siente las bases para un análisis futuro acerca del significado escatológico que el agua tiene en la separación entre el terreno de los vivos y el espacio de los muertos.

Los tres ejemplos analizados en el valle medio del Guadiana, correspondientes a las tres únicas necrópolis excavadas hasta la fecha, se organizan de una forma muy similar en el paisaje: próximos a la confluencia entre el Guadiana y algunos de sus principales afluentes, en áreas que, si no de forma permanente, sí de forma intermitente, quedaban rodeadas de agua, lo que permitía el aislamiento del espacio de enterramiento. Los análisis geográficos realizados muestran que la elección de los puntos para la ubicación de las necrópolis no responde al azar, sino a la perduración de una tradición que se remonta en el tiempo y que, como hemos visto, tiene sus analogías más cercanas en las colonias fenicias de occidente. Así mismo, su ubicación, en las proximidades de la desembocadura de alguno de sus afluentes en el río Guadiana, bien podría emular el patrón fenicio que tiene como principal pauta la ocupación de las desembocaduras de los ríos, de tal modo que, a falta de una salida al mar, en los puntos del interior se ocupan las desembocaduras de los afluentes, lo que al mismo tiempo permite el control de estas arterias de penetración. Estas evidencias muestran además la existencia de un patrón en la elección de los espacios, definido a nivel geográfico, pero que debe ser precisado a nivel simbólico.

Finalmente, la existencia de un patrón confirma la idea de la que parte este estudio, pues parece claro que el modelo detectado en el Guadiana Medio para la ubicación de las necrópolis responde a la

Ediciones Universidad de Salamanca / 어요 perduración de una tradición a la que no son ajenas otras necrópolis del so peninsular.

En este sentido, solo el análisis de diversos núcleos de enterramiento en puntos distintos del so peninsular, o, lo que es lo mismo, solo el análisis del paisaje de las necrópolis del valle del Guadalquivir y Portugal, permitirá ahondar en el simbolismo y el significado que el agua tiene en el registro funerario. En diversas ocasiones se ha aludido a la existencia de unas creencias en torno al tránsito al Más Allá donde los ríos parecen funcionar como elementos de transición (Almagro-Gorbea, 2008b: 895 ) o purificación (Ramos Sainz, 1986), así como el vínculo que se establece entre el culto a la divinidad femenina, caso de Astarté o Tanit, y el agua (Olmos, 1992; Rodríguez Muñoz, 2008); pero lo cierto es que, ante el desconocimiento del paisaje que rodea a las necrópolis del so peninsular, nunca se ha ahondado en el análisis y estudio de este aspecto. Por el contrario, siempre se ha aludido al papel que el agua juega en el imaginario fenicio para así poder deducir su significado en las necrópolis tartésicas (De Jonghe, 2017: 60-61). Frente a ello, solo los trabajos en torno a las necrópolis del área celtibérica han profundizado en el protagonismo que el agua tiene en la separación necrópolis/poblado (Álvarez Sanchís, 1999) al estar incorporada su presencia al 'patrón de asentamiento' que las define. Sin embargo, no parece adecuado trasladar el significado que el agua pueda tener en estas últimas a la realidad detectada en Tarteso, primero, por tratarse de regiones con un sustrato cultural muy diferente y, segundo, por no tratarse de realidades cronológicamente coetáneas. No obstante, la detección de un patrón en la elección de la ubicación de las necrópolis para el valle medio del Guadiana abre una línea de investigación en torno al significado que los cursos de agua tienen en la elección del lugar y su papel dentro de las creencias funerarias del mundo tartésico.

La perduración de una tradición en la elección del enclave de las necrópolis retoma uno de los debates más recurrentes en torno al conocimiento de las necrópolis tartésicas. Nos referimos a la definición de la filiación de los individuos enterrados, pues

Zephyrus, LXXXVIII, julio-diciembre 2021, 87-110 


\section{y la reconstrucción del paleopaisaje funerario de las necrópolis tartésicas}

son amplias las discusiones que atribuyen muchos de estos cementerios a residentes fenicios, a poblaciones híbridas o a indígenas orientalizados; o, lo que es lo mismo, cómo saber si son fenicios que se entierran con su propio ritual o indígenas que han adoptado un ritual fenicio. Aunque este trabajo no puede poner fin a tal debate, sí puede contribuir a su aclaración. Así, dadas las cronologías atribuidas a las necrópolis del valle medio del Guadiana, ss. VII-v a. C., parece que no cabe duda alguna acerca de la filiación de los enterrados, pues ya han transcurrido tres siglos desde que se produjo la colonización hasta el abandono de estas necrópolis, por lo que no parece plausible atribuir estos enterramientos del interior a poblaciones procedentes del Levante. De este modo, cabe pensar que los indígenas adoptarían rituales orientales o simplemente mantendrían una tradición que con anterioridad se había plasmado en el valle del Guadalquivir y la costa atlántica de Portugal, de donde procedían parte de los influjos que posteriormente caracterizarían tanto el modelo de ocupación como los asentamientos del valle medio del Guadiana. Así, a la tradición oriental detectada en la arquitectura, en el registro material o en el rito de cremación presente en las necrópolis del interior, se suman otros aspectos como el hecho de separar el espacio de necrópolis de los poblados por un curso de agua.

Solo los estudios de ADN podrán arrojar un poco más de luz a este respecto, aunque huelga decir que no son abundantes los ejemplos de individuos inhumados. Hasta la fecha, únicamente contamos con los resultados obtenidos en los análisis de ADN de la necrópolis de La Angorrilla, en Alcalá del Río, Sevilla. De los cuatro individuos analizados, solo uno de ellos aportó un resultado positivo que fija su origen europeo o próximooriental; sin embargo, el resultado no ha sido considerado definitivo a falta de un proceso de ampliación de la muestra que permita precisar su origen étnico (Palomo et al., 2014: 629). A este conjunto debemos sumar los restos del enterramiento de la Casa del Carpio, en Belvís de la Jara, Toledo, cuyos resultados de ADN están pendientes de ser publicados. Por último, hemos de añadir los datos procedentes de la inhumación

Ediciones Universidad de Salamanca / 요 de un individuo localizado en la estancia norte del yacimiento de Casas del Turuñuelo, en Guareña, Badajoz, actualmente en fase de estudio. Lamentablemente, pocos resultados podrán extraerse del resto de las necrópolis, en las que predomina el rito de la cremación, por lo que solo el ADN podrá contribuir al conocimiento de la identidad cultural de aquellos que fueron enterrados en las necrópolis tartésicas del so peninsular, dado que la homogeneidad que presentan los ritos de enterramiento y sus ajuares poco podrá aportar a este respecto.

Al margen de la identidad de los individuos enterrados en las necrópolis tartésicas, lo cierto es que este trabajo nos permite acercarnos un poco más al ritual emulado y respetado en las mismas, incorporando la ubicación como una pauta más dentro del patrón de enterramiento. Una vez más, el uso de datos espaciales, como el LidAR y la fotografía histórica, ha puesto de relieve su utilidad para la reconstrucción y estudio del paisaje antiguo (Cerrillo y López, 2020), que en esta ocasión se ha puesto al servicio del conocimiento de la elección de los lugares para la ubicación de las necrópolis de la I Edad del Hierro del so peninsular. Aunque todavía queda un largo camino por recorrer, este trabajo y la metodología que recoge sirven de antesala para comenzar un estudio mucho más amplio que incluya las necrópolis tanto de las colonias fenicias de occidente como las tartésicas del valle del Guadalquivir y otros puntos del Guadiana, que permita ahondar en el conocimiento del origen y significado del patrón de asentamiento de estos espacios destinados al descanso eterno.

\section{Bibliografía}

Almagro-Gorbea, M. (1970): "Hallazgo de un kylix ático en Medellín (Badajoz)". En Actas XI Congreso Nacional de Arqueología. Zaragoza, pp. 437-468.

Almagro-Gorbea, M. (1977): El Bronce Final y el Periodo Orientalizante en Extremadura. Bibliotheca Praehistorica Hispana, 14. Madrid: csic.

Almagro-Gorbea, M. (1996): Ideología y poder en Tartessos y el mundo ibérico. Madrid: RAH. 
Almagro-Gorbea, M. (2006a): "Situación y topografía del yacimiento". En Almagro-Gorbea, M. (dir.): La necrópolis de Medellín. I. La excavación y sus hallazgos. Madrid: RAH, pp. 15-20.

Almagro-Gorbea, M. (2006b): "Historia de la investigación”. En Almagro-Gorbea, M. (dir.): La necrópolis de Medellin. I. La excavación y sus hallazgos. Madrid: RAH, pp. 21-33.

Almagro-Gorbea, M. (2006c): "Descripción de los hallazgos". En Almagro-Gorbea, M. (dir.): La necrópolis de Medellin. I. La excavación y sus hallazgos. Madrid: RAH, pp. 35-39.

Almagro-Gorbea, M. (2006d): "Campaña de 1982. Cuadrícula 82”. En Almagro-Gorbea, M. (dir.): La necrópolis de Medellín. I. La excavación y sus hallazgos. Madrid: RAH, pp. 99-133.

Almagro-Gorbea, M. (2008a): "Cronología”. En AlMAgro-Gorbea, M. (dir.): La necrópolis de Medellín. III. Estudios Analíticos, IV. Interpretación de la necrópolis, V: El marco histórico de Medellin-Conisturgis. Madrid: RAH, pp. 881-892.

Almagro-Gorbea, M. (2008b): "La topografía de la necrópolis: estructura y evolución". En ALMAGro-GorBEA, M. (dir.): La necrópolis de Medellín. III. Estudios Analíticos, IV. Interpretación de la necrópolis, v: El marco histórico de Medellin-Conisturgis. Madrid: RAH, pp. 893-906.

Almagro-Gorbea, M. (2008c): "Ritos y creencias". En Almagro-Gorbea, M. (dir.): La necrópolis de Medellin. III. Estudios Analiticos, IV. Interpretación de la necrópolis, v: El marco histórico de Medellin-Conisturgis. Madrid: RAH, pp. 949-1003.

Almagro-Gorbea, M. (2017): "Paisaje y estructuras funerarias de la necrópolis de Medellín". En Adroit, S. y Graells, R. (eds.): Arquitecturas funerarias y memoria. La gestión de las necrópolis en Europa occidental (ss. X-III a. C.). Archeologia Nuova Serie, 4. Toulouse: Osanna Edizioni, pp. 143-166.

Álvarez Martí Aguilar, M. (2009): "Identidad y etnia en Tartessos”, Arqueología Espacial, 27, pp. 79-112.

Álvarez Martí Aguilar, M. (2010): "Tartesios: un etnónimo de la Iberia púnica”, Mainake, xxxiI (1), pp. 395-406.

Álvarez Martínez, J. M. (1984): "Consideraciones sobre la Mérida prerromana”, Revista de Estudios Extremeños, LX (1), pp. 101-110.

Álvarez Sanchís, J. (1999): Los Vettones. Madrid: rah.

Aubet, M. ${ }^{a}$ E. (1987): Tiro y las colonias fenicias de occidente. Barcelona: Bellaterra.
Aubet, M. ${ }^{a}$ E.; Núñez, F. J. y Trellisó, L. (2004): "La necrópolis fenicia de Tiro-Al Bass en el contexto funerario fenicio oriental", Huelva Arqueológica, 20, pp. 43-61.

Belén Deamos, M. (2001): "La cremación en las necrópolis tartésicas". En García Huertas, R. y MoraLES, J. (eds.): Arqueologia funeraria: las necrópolis de incineración. Cuenca: Univ. de Castilla-La Mancha, pp. 37-78.

Bonsor, G. (1899): "Les colonies agricoles pré-romaines de la vallée du Bétis”, Revue Archéologique, 35, pp. 129-159.

Celestino, S. (2005): "El Período Orientalizante en Extremadura y la colonización tartésica del interior". En Celesstino, S. y Jiménez Ávila, J. (eds.): El Periodo Orientalizante. Anejos de Archivo Español de Arqueología, xxxv. Madrid: Csic, vol. 2, pp. 767-786.

Celestino, S. y López Ruiz, C. (2020): Tarteso y los fenicios de occidente. Córdoba: Almuzara.

Celestino, S. y Rodríguez González, E. (2017): "Tarteso en Extremadura", Revista de Estudios Extremeños, LXXIII (1), pp. 13-56.

Cerrillo, E. y López López, A. (2020): "Evaluación y perspectivas de uso del Lidar en la arqueología espańola", Boletín del MAN, 39, pp. 219-236.

De Jonghe, M. (2017): “A propósito de la organización en las necrópolis fenicias de la Península Ibérica”. En Adroit, S. y Graells, R. (eds.): Arquitecturas funerarias y memorias: la gestión de las necrópolis en Europa Occidental (ss. X-III a. C.). Archeologia Nuova Serie, 4. Toulousse: Osanna Edizioni, pp. 59-73.

EnRíqueZ, J. J. (1991): "Los restos de la necrópolis de la desembocadura del río Aljucén dentro del contexto orientalizante extremeño". En Extremadura Arqueológica, II, pp. 175-183.

Enríquez, J. J. y Domínguez de la Concha, C. (1991): "Restos de una necrópolis orientalizante en la desembocadura del río Aljucén (Mérida, Badajoz)", Saguntum, 24, pp. 35-52.

Fernández Flores, A.; Rodríguez Azogue, A. y Prados, E. (2014): "La ciudad y el territorio". En Fernández Flores, A.; Rodríguez Azogue, A.; Casado, M. y Prados, E. (coords.): La necrópolis de época tartésica de La Angorrilla (Alcalá del Río, Sevilla). Sevilla: Univ. de Sevilla, pp. 17-39.

Frendo, A. J.; De Trafford, A. y Vella, N. C. (2005): "Water journeys of the dead: a glimpse into Phoenician and Punic eschatology". En Spanò GiammellaRo, A. (ed.): Atti V Congresso Internazionale di Studi 
y la reconstrucción del paleopaisaje funerario de las necrópolis tartésicas

Fenici e Punici. Palermo: Univ. de Palermo, pp. 427443.

García, E.; Marzoli, D.; Cabaco, B.; Heubner, B. y Gamer-Wallert, I. (2016): "El descubrimiento de la necrópolis fenicia de Ayamonte, Huelva (ss. vIII-VII a. C.)". En JimÉnez Ávila, J. (ed.): Sidereum Ana III. El río Guadiana y Tartessos. Mérida: Consorcio de la Ciudad Monumental, pp. 493-530.

Gómez Peña, A. (2018): "Religión e identidad en Tarteso a través del registro funerario de la Caura protohistórica”. En Escacena, J. L.; Gómez Peña, A. y Pérez Aguilar, L. G. (coords.): Caura. Arqueología en el estuario del Guadalquivir. Spal Monografías Arqueología, xxvi. Sevilla: Univ. de Sevilla, pp. 181199.

Gras, M.; Rouillard, P. y Teixidor, J. (1991): El universo fenicio. Barcelona: Mondadori.

Jiménez Ávila, J. (2016): “Ancha es Tartessos. El Periodo Orientalizante (ss. viII-vi a. C.) en el tramo extremeño del Guadiana”. En Jiménez Ávila, J. (ed.): Sidereum Ana III. El río Guadiana y Tartessos. Serie Compacta, 1. Mérida: Consorcio de la Ciudad Monumental, pp. 69-106.

Menéndez, A.; Gibello, V. y Jiménez Ávila, J. (2015): "El ajuar de la tumba XLVI de la necrópolis orientalizante de Valdelagrulla (Medellín, Badajoz)". En Medina, N. (coord.): VII Encuentro de Arqueología del Suroeste Peninsular. Aroche: Ayto. de Aroche, pp. 454-473.

Menéndez, A.; Sanabria, D.; Sánchez Hidalgo, F.; Gibello, V. y Jiménez Ávila, J. (2013): "La necrópolis orientalizante de Valdelagrulla (Medellín, Badajoz). Datos preliminares”. En Jiménez, J.; Bustamante, M. y Díaz Cabezas, M. (eds.): vi Encuentro de Arqueología del Suroeste. Villafranca de los Barros: Ayto. de Villafranca de los Barros, pp. 10001029.

Monterroso, A. (2019): "Geoarcheological Characterisation of Sites of Iberian and Roman Cordoba Using LidAR Data Acquisitions", Geosciences, 9-205, pp. 1-17. doi: 10.3390/geosciences 9050205 .

Olmos, R. (1992): "Iconografía y culto a las aguas de época prerromana en los mundos colonial e ibérico", Espacio, Tiempo y Forma, serie II, 5, pp. 103-120.

Paloma, S.; Fernández Domínguez, E.; Gamba, C. y Prados, E. (2014): "Estudio de adN mitocondrial de los restos humanos hallados en La Angorrilla (Alcalá del Río, Sevilla)". En Fernández Flores, A.; Rodríguez Azogue, A.; Casado, M. y Prados, E. (coords.): La necrópolis de época tartésica de la
Angorrilla (Alcalá del Río, Sevilla). Sevilla: Univ. de Sevilla, pp. 617-631.

Pellicer, M. (2004): "De Laurita a Tavira: una perspectiva sobre el mundo funerario en Occidente". En González Prats, A. (ed.): El mundo funerario. Actas III Seminario Internacional sobre temas fenicios. Alicante: Univ. de Alicante, pp. 13-42.

Pla, R. (2014): “Tipo 43. Tinajas o pithoi". En GonZÁlez Prats, A. (coord.): La Fonteta-2. Estudio de los materiales arqueológicos hallados en la colonia fenicia de la actual desembocadura del rio Segura (Guardamar, Alicante). Alicante: Univ. de Alicante, t. 2, pp. 691-728.

Ramos, M. L. (1986): Estudio sobre el ritual funerario en las necrópolis fenicias y punicas de la Península Ibérica. Madrid: Univ. Autónoma de Madrid.

Rodríguez Díaz, A.; Pavón, I. y Duque, D. (2004): “'La Mata' y su territorio". En Rodríguez Díaz, A. (ed.): El edificio protohistórico de 'La Mata' (Campanario, Badajoz) y su entorno territorial. Cáceres: Univ. de Extremadura, pp. 497-569.

Rodríguez González, E. (2018): El poblamiento del valle medio del Guadiana durante la I Edad del Hierro. Bibliotheca Praehistorica Hispana, xxxiv. Madrid: csic.

Rodríguez GonzÁlez, E. (2020a): “Tarteso y lo orientalizante. Una revisión historiográfica de una confusión terminológica y su aplicación a la cuenca media del Guadiana”, Lucentum, 39, pp. 113-129. doi: 10.14198/LVCENTVM2020.39.06.

Rodríguez GonZÁlez, E. (2020b): “¿Y los campesinos dónde están? Una propuesta de análisis para el estudio del campesinado y su aplicación en el valle medio del Guadiana durante la I Edad del Hierro", Complutum, 31-32, pp. 277-301. doi: 10.5209/cmpl.72485.

Rodríguez Muñoz, R. (2008): "El uso cúltico del agua en el mundo fenicio y púnico. El caso de Astarté en Cádiz”, Herakleion, 1, pp. 21-40.

Ruiz Delgado, M. a M. (1983): "Situación geográfica". En Aubet, M. ${ }^{a}$ E.; Serna, M. ${ }^{a}$ R.; Escacena, J. L. y Ruiz Delgado, M.a M. (eds.): La Mesa de Setefilla. Lora del Río (Sevilla). Campaña de 1979. Madrid: Ministerio de Cultura, pp. 11-16.

Ruiz Delgado, M. ${ }^{a}$ M. (1989): "Las necrópolis tartésicas: prestigio, poder, jerarquías". En AUBET, M. ${ }^{a}$ E. (coord.): Tartessos: arqueología de la protohistoria del bajo Guadalquivir. Sabadell: Ausa, pp. 247-286.

Ruiz Gálvez, M. (1995): "El significado de la Ría de Huelva en el contexto de las relaciones de intercambio y de las transformaciones producidas en la transición Bronce Final/Edad del Hierro”. En Ruiz 
Gálvez, M. (ed.): Ritos de paso y puntos de paso: la Ría de Huelva en el mundo del Broce Final Europeo. Complutum Extra, 5. Madrid, pp. 129-155.

Ruiz Mata, D. y Pérez, C. (1995): “Aspectos funerarios en el mundo orientalizante y colonial de Andalucía occidental". En FÁbregas, R.; Pérez, F.; FernánDEz, F. (eds.): Arqueoloxía da Morte na Peninsula Ibérica desde as Orixes ata o Medievo. Vigo: Concello de Xinzo de Limia, pp. 169-221.

TORres, M. (1999): Sociedad y mundo funerario en Tartessos. Madrid: RAH.
Torres, M. (2005): "Las necrópolis orientalizantes del sudoeste de la Península Ibérica”. En Celestino, S. y Jiménez Ávila, J. (eds.): El Periodo Orientalizante. Anejos de Archivo Español de Arqueología, xxxv. Mérida: csic, vol. 1, pp. 423-440.

Torres, M. (2017): "El paisaje funerario de las necrópolis tartésicas". En Adroit, S. y Graells, R. (eds.): Arquitecturas funerarias y memoria: la gestación de las necrópolis en Europa occidental (ss. X-III a. C.). Archeologia Nuova Serie, 4. Toulousse: Osanna Edizioni, pp. 359-398. 